\title{
Off-Site Calibration Approach of EnviroScan Capacitance Probe to Assist Operational Field Applications
}

\author{
Daniel Kibirige * and Endre Dobos
}

check for updates

Citation: Kibirige, D.; Dobos, E. Off-Site Calibration Approach of EnviroScan Capacitance Probe to Assist Operational Field Applications. Water 2021, 13, 837. https://doi.org/ $10.3390 / w 13060837$

Academic Editors: Ying Zhao and Guido D’Urso

Received: 20 January 2021

Accepted: 16 March 2021

Published: 19 March 2021

Publisher's Note: MDPI stays neutral with regard to jurisdictional claims in published maps and institutional affiliations.

Copyright: (c) 2021 by the authors. Licensee MDPI, Basel, Switzerland. This article is an open access article distributed under the terms and conditions of the Creative Commons Attribution (CC BY) license (https:// creativecommons.org/licenses/by/ $4.0 /)$.
Institute of Geography and Geoinformatics, University of Miskolc, 3515 Miskolc-Egyetemváros, Hungary; ecodobos@uni-miskolc.hu

* Correspondence: ecodan@uni-miskolc.hu; Tel.: +36-46-565-1816

\begin{abstract}
Soil water content or soil moisture content is considered one of the most critical properties of the soil for crop production, irrigation, and environmental studies. The technical development of soil moisture measurement devices is swift, but calibration among field conditions is still not entirely resolved. Accurate calibration requires samples taken right next to the sensor that disturbs the site and changes the soil conditions. Real field operation requires the probe to represent larger areas that have undisturbed soils around the probe. These would describe the parcel's general soil conditions and start providing data from the time of installation. This study aimed to compare several potential solutions for off-site calibration of an operational EnviroScan sensor (Sentek Technologies, Stepney South, Australia). The performances of the default and soil texture-specific equations provided by the manufacturer were compared with the field and laboratory calibration approaches. Two statistical parameters, coefficient of determination $\left(\mathrm{R}^{2}\right)$ and root square mean error (RMSE) was used to determine logarithmic model results. The results show that the default calibration equations in all three classes have relatively low performances with RMSE values of around 10-15 and $\mathrm{R}^{2}$ values ranging from 0.4 to 0.8 . However, significant refinement was achieved by selecting texture-specific equations from the manufacturer's libraries. The soil texture-specific equations of the EnviroScan often yielded quite satisfactory results, with RMSEs ranging between 2 and 4. Similar RMSE values were achieved from the laboratory calibration exercises, but the reapplication potential of these equations was often questionable due to the severely changed soil conditions of the laboratory processed soil compared to the field soil conditions.
\end{abstract}

Keywords: Sentek capacitance probe; soil water content; calibration

\section{Introduction}

Soil water content (SWC) or soil moisture content is considered as one of the most critical properties of the soil for crop production, irrigation, and functioning of terrestrial ecosystems. The vertical and lateral flow of water on earth and through the soil determines patterns of eluviation and illuviation [1]. In particular, it strongly affects the land surface fluxes for water and energy balances, thereby influencing the temperature, evapotranspiration, and runoff generation and supporting the growth of vegetation [2]. To date, accurate monitoring of soil moisture is critical for many environmental and hydrological applications, and commercial sensors have been used widely to detect the soil water content [3]. Many soil water content sensors are currently available to assist in the scheduling of irrigation and aid in soil science research. Some of these include tensiometers (measure soil water tension or suction [4]), neutron probes (measure moisture content in soil through by recording back-scattered slow neutrons [5]), and capacitance-based (made up of multiple sensors that measure the electrical field frequency used by the device or measure the dielectric constant of the soil media surrounding it) sensors, i.e., frequency domain reflectometry (FDR) $[3,6,7]$. FDR sensors have been used mainly as equipment for indirect measurements of SWC because they allow an easy and non-destructive [8] method of measurement if compared with traditional methods. Mazahrih et al. [9] underlined the importance of soil 
moisture sensors operating in plastic access tubes inserted in the soil, i.e., downhole soil moisture sensors, for research and precision irrigation scheduling. Downhole sensors have the advantage of being mounted with minimum soil disruption around the entry tube relative to other soil moisture sensors, meaning that it is not required to excavate any soil pits and test soil water content over a soil profile. Among the downhole sensors, there are Sentek (Sentek Technologies, Stepney South, Australia) soil moisture sensors.

The Sentek soil moisture sensors were initially made available to the general research community to measure soil water content. Later it was integrated into operational irrigation controlling/scheduling systems. Sentek (Sentek Technologies, Australia) soil moisture sensors originate from Australia, though they have been used in other parts of the world [10]. They compromise three sensors-stand-alone sensors (EnviroScan and Drill \& Drop) and portable probes (Diviner 2000 probes). In this paper, stand-alone probes (herein called EnviroScan) were used as the investigation instrument.

The EnviroScan sensor is a stand-alone continuous soil water monitoring system [11]. It is acclaimed as one of the world's leading irrigation monitoring and scheduling device by growers and researchers [3,11]. The EnviroScan sensor consists of a network of probes that support an array of sensors for soil water. The sensors continuously monitor soil water changes, highlighting the crop's dynamic water use in environmental conditions and irrigation management strategies.

Several methods for measuring soil water content have been developed that utilize the dielectric constant of the soil, water, and air to determine volumetric water content $\left(\theta_{\mathrm{v}}\right)$. The dielectric constant of pure water at $20{ }^{\circ} \mathrm{C}$ is 80.4 , soil material is between 3 and 7 , and the air is 1 . Capacitance devices respond to small changes in $\theta_{\mathrm{v}}$ because a relatively small amount of water with its high dielectric constant can significantly increase the average dielectric constant of soil, air, and water mixture. Since the soil's electrical capacitance changes with soil type, limitations occur in gravelly and coarse stony soils where air spaces are more abundant than finer soils, and the soil's overall capacitance is low. These methods must be calibrated to the specific soil textures due to differences in dielectric behavior from soil physical and chemical properties.

This technology is spreading fast in irrigation control. Reliable measurements require the probe to be deployed on representative positions having the same soil conditions as the rest of the field. Therefore, it needs to be deployed right after the seedbed creation and sowing to ensure the same soil conditions that the crop is growing on. Any disturbance that makes the site different from the field conditions limits the accuracy and reliability. This makes the "traditional" calibration unsuitable for operational sensors, when calibration has to be done fast, right after the deployment, to assist the irrigation from the beginning of the vegetation period. There is no time for long field calibration, and any local disturbance around the probe-like sampling-would change the sites' soil conditions.

To date, a vast amount of literature (Table 1) on calibration equations has been conducted. Most of the authors suggest that the Sentek default manufacturer's calibration equations need to be calibrated to specific soil textures to achieve the most accurate estimation of volumetric water content. So, the EnviroScan sensor requires soil-specific calibrations to produce accurate estimates of soil water content due to the large variability in soils. A measuring instrument's calibration is made by aligning that instrument's readings against values determined by a long-established method and accepted as a standard method for measuring the same value.

Several calibration procedures have been conducted in the laboratory [12-16] and field conditions [17-19]. Both environments' results support the accuracy of the capacitance sensors improved when the system was calibrated for specific soil textures [20]. Furthermore, other studies proved the default Sentek manufacturer's equations overestimate soil moisture content in coarse-textured soils [21], silty sand [20], silty loam [22], and underestimate in sandy soils [17]. 
Table 1. Summary of literature on Sentek EnviroScan and Diviner 2000 probes and other various capacitance probes.

\begin{tabular}{|c|c|c|c|c|c|}
\hline Source & Sensor/s & Methodology & Soil Texture & Results & Conclusions \\
\hline Sentek Manufacturer [23] & EnviroScan & $\begin{array}{l}\text { Exponential regression } \\
\text { analysis. }\end{array}$ & $\begin{array}{l}\text { Sand, loam, clay loam, } \\
\text { sandy loam, clay, and } \\
\text { textured crackling clay }\end{array}$ & $\begin{array}{c}\text { Sand, loam, clay loam: } \mathrm{R}^{2}-0.97 \text {, sand, sandy } \\
\text { loam, clay: } \mathrm{R}^{2}-0.99 \text { and Uniform crackling } \\
\text { clay: } \mathrm{R}^{2}-0.5\end{array}$ & - \\
\hline Paltineanu and Starr [13] & EnviroScan & $\begin{array}{l}\text { Nonlinear models were used } \\
\text { for regression analysis. }\end{array}$ & Silt loam & $\mathrm{R}^{2}-0.99, \mathrm{RMSE}-0.009$ & $\begin{array}{l}\text { More calibration research with these } \\
\text { capacitance sensors was needed for } \\
\text { special soils (e.g., swelling 2:1 clays or } \\
\text { high organic matter content). }\end{array}$ \\
\hline Morgan et al. [17] & EnviroScan & $\begin{array}{l}\text { Linear and exponential models } \\
\text { were used for regression } \\
\text { analysis. }\end{array}$ & Fine sand & $\mathrm{R}^{2}-0.83, \mathrm{RMSE}-0.009$ & $\begin{array}{l}\text { Default calibration equations-yielded } \\
22 \% \text { lower estimates than data regression. } \\
\text { The exponential relationship provided the } \\
\text { best fit. }\end{array}$ \\
\hline Evett et al. [24] & $\begin{array}{l}\text { SM neutron probe (SMNP), } \\
\text { EnviroScan, Diviner 2000, } \\
\text { IMKO Trime tube probe }\end{array}$ & $\begin{array}{l}\text { Preliminary calibration } \\
\text { compared with gravimetric } \\
\text { sampling. }\end{array}$ & $\begin{array}{l}\text { Sand, Silt loam, Sandy } \\
\text { loam, Clay loam, Silty clay } \\
\text { loam \& clay }\end{array}$ & $\mathrm{R}^{2}>0.9, \mathrm{RMSE}<0.01$ & $\begin{array}{l}\text { EnviroScan-overestimated water } \\
\text { content near saturation and } \\
\text { underestimated it near wilting point. The } \\
\text { plant available water capacity measured } \\
\text { by the EnviroScan system was twice that } \\
\text { indicated by laboratory measurements. }\end{array}$ \\
\hline Leib et al. [25] & $\begin{array}{l}\text { EnviroScan and other } \\
\text { sensors }\end{array}$ & $\begin{array}{l}\text { Statistical evaluation of } \\
\text { numerous sensors for their } \\
\text { ability to estimate water } \\
\text { content. }\end{array}$ & Silt loam soil & $\begin{array}{c}\text { EnviroScan: } \mathrm{R}^{2}-0.94 \text { to } 0.95, \mathrm{RRMSE}-59 \% \text { to } \\
68 \%\end{array}$ & $\begin{array}{l}\text { Soil-specific calibration of each sensor is } \\
\text { necessary to obtain a high degree of } \\
\text { absolute accuracy in SWC measurements. }\end{array}$ \\
\hline Geesing et al. [22] & $\begin{array}{l}\text { Diviner handheld } \\
\text { capacitance probe }\end{array}$ & $\begin{array}{l}\text { Exponential regression was } \\
\text { fitted to the model. }\end{array}$ & $\begin{array}{l}\text { Site A-Silt-loamy } \\
\text { Site B-loam }\end{array}$ & $\begin{array}{l}\text { Site A: } R^{2}-0.93, \text { RMSE-0.04 } \\
\text { Site B: } R^{2}-0.88, \text { RMSE-0.03 }\end{array}$ & $\begin{array}{l}\text { Site A-underestimated the SWC. Site } \\
\text { B-overestimated SWC. At field } \\
\text { level—-the model performed better than } \\
\text { the manufacturer's calibration and the } \\
\text { calibration proposed by Paltineanu and } \\
\text { Starr (1997). }\end{array}$ \\
\hline Groves and Rose [26] & Diviner 2000 & $\begin{array}{l}\text { Calibration equations, derived } \\
\text { by regression analysis. }\end{array}$ & $\begin{array}{l}\text { Sandy loam, Silty clay } \\
\text { loam, Clay and Organic } \\
\text { sandy clay loam }\end{array}$ & $\mathrm{R}^{2}>0.93$ for all & $\begin{array}{l}\text { The natural heterogeneity of field soils } \\
\text { adversely affected the accuracy of such } \\
\text { methods. }\end{array}$ \\
\hline Jabro et al. [21] & $\begin{array}{c}\text { EnviroScan and Neutron } \\
\text { probe }\end{array}$ & $\begin{array}{l}\text { Statistically compared } \\
\text { calibrated soil water content } \\
\text { results with those estimated by } \\
\text { the uncalibrated equation. }\end{array}$ & Silt loam & $\begin{array}{c}\text { Default \& calibrated } \\
\text { 1998: } \mathrm{R}^{2} \_0.95 \text { and } 0.96 \text {, RRMSE: } 67 \% \text { and } 7 \% \text {. } \\
\text { 1999: } \mathrm{R}^{2} \_0.94 \text { and } 0.95 \text {, RRMSE: } 59 \% \text { and } 41 \% \text {. } \\
\text { 2000: } \mathrm{R}^{2} \_0.94 \text { and } 0.91 \text {, RRMSE: } 66 \% \text { and } 40 \% \text {. } \\
\text { Calibrated equation } 1998-2000 ; \text { RRMSE: } 7 \% \text {, } \\
41 \%, 40 \% \\
\text { Uncalibrated RRMSE: } 68 \%, 59 \% \text {, and } 66 \%\end{array}$ & $\begin{array}{l}\text { Results supported that the site calibration } \\
\text { equation gave more accurate estimates of } \\
\text { individual values (low RRMSE) of } \\
\text { volumetric SWC than those obtained } \\
\text { from the uncalibrated equation. }\end{array}$ \\
\hline
\end{tabular}


Table 1. Cont.

Source

Sensor/s

Methodology the soil water content of a

shrinking-swelling clay soil.
Field calibrations-measured
Soil Texture

Clay

Neuron Probe: $\mathrm{R}^{2}-0.87$, Diviner: $\mathrm{R}^{2}-0.80$
Default or laboratory determined Duations differed from literature for a shrinking-swelling clay for both neutro probe and Diviner 2000 sensors. By using the field, rather than the default, calibrations, the two instruments gave similar estimates of the change to water content.

All of the devices required soil-specific calibrations to achieve accuracies better than 0.04 .

Manufacturer's default equation-over calculated $\theta_{\mathrm{v}}(\mathrm{RMSE}>0.044)$ Capacitance probe $(\mathrm{CP})$ calibration equations-provided accurate $\theta_{\mathrm{v}}$
Compared the errors in evaluating $\theta_{\mathrm{v}}$ when using soil-specific equations as

Loam, silt loam, and clay soil-specific equations as

loam default equation.
Lab: $R^{2}$ \& RMSE, Manufacturer: 0.73 and 0.051 With intercept-0.96, 0.027, and Without intercept -0.96 and 0.027

Manufacturer- 0.88 and 0.44 , With intercept $-0.92,0.024$, and Without intercep

$$
0.92 \text { and } 0.024
$$

determinations (RMSE < 0.028). Accuracy

of $\mathrm{CP}$ in monitoring $\theta_{\mathrm{v}}$ under field

conditions was slightly better using the

laboratory calibration equation (RMSE -

$0.019)$ rather than the field calibration equation (RMSE $=0.023$ ).

Equations exported from the local

calibration outweigh the ones in literature and from the manufacturer default equation.

Tensiometers were more accurate than the EnviroScan and Watermark systems without the site-specific calibration. EnviroScan probe overestimated SWC while the Waterork while the Waternark and tensiometer sensors underestimated it. Site-specific calibration will be needed to improve their accuracy in estimating soil water content data.

Manufacturer's calibration
Field and laboratory measurements were done to

$\theta_{\mathrm{v}}$ and SF. refine the relationship between
Coarse-textured reconstructed soils
EnviroScan: $\mathrm{R}^{2}-0.94$ to 0.96 , RRMSE- 16.8 to 19.17, Watermark 200SS: $R^{2}-0.89$ to 0.93 , RRMSE-8.6 to 11.3 , Tensiometer: $R^{2}-0.91$ to 0.95
Zettl et al. [30]

EnviroScan
Field: $R^{2}-0.933$ to 0.974 and Lab: $R^{2}-0.955$ to 0.966 equation-underestimate $\theta_{\mathrm{v}}$ under wet conditions. Calibration improves th application of the EnviroScan for 
Table 1. Cont

\begin{tabular}{|c|c|c|c|c|c|}
\hline Source & Sensor/s & Methodology & Soil Texture & Results & Conclusions \\
\hline Al-Ghobari et al. [11] & EnviroScan & $\begin{array}{c}\text { An artificial neural network } \\
\text { (ANN) was used to calibrate } \\
\text { SWC compared with a } \\
\text { regression analysis derived } \\
\text { SWC. }\end{array}$ & Sandy clay loam & $\begin{array}{l}\text { Regression of } S F \text { vs. gravimetric method: } \\
\mathrm{R}^{2}-0.9225 \text {. Gravimetric method vs. ANN } \\
\text { model: } \mathrm{R}^{2}-0.9928\end{array}$ & $\begin{array}{l}\text { ANN technique could be an effective } \\
\text { alternative calibration method for } \\
\text { estimating soil water content using the } \\
\text { EnviroScan sensor. }\end{array}$ \\
\hline Provenzano et al. [31] & Diviner 2000 & $\begin{array}{l}\text { Regression fitting using field } \\
\text { and laboratory calibration } \\
\text { protocols. }\end{array}$ & $\begin{array}{l}\text { Seven soil types in } \\
\text { different regions are } \\
\text { characterized by different } \\
\text { particle size distributions } \\
\text { and shrink/swell potential. }\end{array}$ & $\begin{array}{c}\text { Undisturbed monoliths: } \mathrm{R}^{2}-0.84 \text { to } 0.95 \\
\text { RMSE- } 0.015 \text { to } 0.053 \\
\text { Default calibration: RMSE- }-0.05 \text { to } 0.166 \\
\text { Regression fitting: } \mathrm{R}^{2}-0.35 \text { to } 0.87 \text {, RMSE- } 0.04 \\
\text { to } 0.121\end{array}$ & $\begin{array}{l}\text { Field calibration-default calibration } \\
\text { equation considered valid. Soil-specific } \\
\text { calibration-improved estimation of } \theta_{\mathrm{V}} \\
\text { and RMSE to values were lower than } \\
\text { default calibration. }\end{array}$ \\
\hline Gao et al. [32] & $\begin{array}{l}\text { Proposed probe and } \\
\text { Diviner } 2000\end{array}$ & $\begin{array}{l}\text { Compared probes: Proposed } \\
\text { probe-Lab testing. Proposed } \\
\text { probe + Diviner 2000-Field } \\
\text { testing. }\end{array}$ & Sandy loam and clay loam & $\begin{array}{l}\text { Proposed probe: } R^{2}-0.9644 \text { and RMSE- }-0.0423 \text {. } \\
\text { Diviner 2000: } R^{2}-0.86 \text { and RMSE-1.75 }\end{array}$ & $\begin{array}{l}\text { Both sensors were adaptable to the } \\
\text { measurement of the volumetric moisture } \\
\text { content of various soil types. }\end{array}$ \\
\hline Roberti et al. [1] & EnviroScan and TriSCAN & $\begin{array}{l}\text { A semi-automated production } \\
\text { process that derived } \theta_{\mathrm{v}} \\
\text { measurements. }\end{array}$ & Clay and Sand & $\begin{array}{l}\text { Default calibration fit: RMSE-0.123 } \\
\text { Soil-specific coefficients: RMSE-0.017 }\end{array}$ & $\begin{array}{l}\text { Soil-specific coefficients improved RMSE } \\
\text { in clay and sandy soils. }\end{array}$ \\
\hline Campora et al. [14] & $\begin{array}{l}\text { Drill \& Drop, Sentek } \\
\text { Sensor Technologies }\end{array}$ & $\begin{array}{c}\text { Linear Regression and Multiple } \\
\text { Linear Regression analysis } \\
\text { fitting- } \theta_{\mathrm{V}} \text { and the mean grain } \\
\text { size, D50 as independent } \\
\text { variables. }\end{array}$ & Fine sand & $\begin{array}{c}\text { LR: } \mathrm{R}^{2}-0.96 \text { to } 0.99 \\
\text { RMSE-1.4\% to } 2.8 \% \\
\text { MLR: } \mathrm{R}^{2}-0.97 \text { and RMSE-2.41\%, }\end{array}$ & $\begin{array}{l}\text { Results highlighted the need for } \\
\text { soil-specific calibration. }\end{array}$ \\
\hline Jia et al. [2] & $\begin{array}{l}\text { TDR-315 L and Diviner } \\
2000\end{array}$ & $\begin{array}{l}\text { Multiple linear regression } \\
\text { (MLR)—compared Gravimetric } \\
\text { volumetric water content } \\
\text { (VWC) and modeled VWC. }\end{array}$ & Sand & $\begin{array}{l}\text { TDR-315 L: } \mathrm{R}^{2}-0.9820, \text { RMSE-0.0255 } \\
\text { Diviner 2000: } \mathrm{R}^{2}-0.9233, \text { RMSE-0.053 }\end{array}$ & $\begin{array}{l}\text { TDR-315L-more accurate than Diviner } \\
\text { 2000. Diviner 2000-poor in moist soils. } \\
\text { Accuracy under laboratory conditions } \\
\text { improved significantly by applying the } \\
\text { calibration method. }\end{array}$ \\
\hline Provenzano et al. [16] & Diviner 2000 & $\begin{array}{l}\text { Gravimetric measurements } \\
\text { compared to laboratory } \\
\text { calibrated VWC. }\end{array}$ & $\begin{array}{l}\text { Loamy Sand, Sandy Clay } \\
\text { Loam, Clay Loam, and } \\
\text { Clay }\end{array}$ & $\begin{array}{l}\text { Root mean square error (RMSE) was lower than } \\
0.049 \mathrm{~cm}^{3} \mathrm{~cm}^{-3} \text { in all soil textures }\end{array}$ & $\begin{array}{l}\text { A new model to estimate VWC using soil } \\
\text { bulk density as an independent variable }\end{array}$ \\
\hline
\end{tabular}


Consequently, if uncalibrated equations are used to determine the soil water content, there is a strong likelihood of a high percentage difference in overestimated and underestimated water content. The proposed manufacturer calibration procedure for the EnviroScan and the Diviner 2000 [10] is not always possible. This led the scientists to use either laboratory or field methods to obtain calibration equations, and many times they also used already derived calibration equations in literature. However, none of these approaches is ideal. Field calibrations require bulk sampling right next to the probe that destroys the site. This can be done only afterward, which is not an option for operational use. Laboratory calibration is done using disturbed soil that does not necessarily represent the soils' real field conditions. With this in mind, this study aimed to develop and test off-site and laboratory calibration approaches to assist quick and easy development of estimation equations or the selection of the best fitting equation from the manufacturer's library. This was done by comparing three approaches that were similar though their purpose was very specific. The difference between our study to other studies was that we aimed to calibrate the sensor without disturbing the site-mainly off-site sampling for calibration - and compared the approach using the same soil material with all known calibration techniques described in the literature. This approach gives innovation to our study. It highlights the advantages and disadvantages of the different approaches when quick deployment and site-specific calibration are needed for immediate operation and data supply in any location, like in irrigation control. In the long run, this will give a direct indication to agronomists when and how much to irrigate-saving them large amounts of water. To achieve this, sensors have to be operational from deployment to assist the technology throughout the entire vegetation period. Therefore, the objectives of the study were (i) to compare the calibration equations obtained in the laboratory and field-offsite of the sensor - for EnviroScan sensor in three different textures, namely sand, loam, and clay soils; (ii) to compare statistical errors between field and laboratory calibration techniques in evaluating soil water when using soil-specific equations as opposed to the manufacturer's default equation; (iii) assess the accuracy of EnviroScan sensor under field conditions using the default manufacturer's calibration equation and the calibration equations developed from the regression analysis. Finally, the derived equation was applied to the loam site to test its accuracy on the EnviroScan sensor, and the results were compared to the manufactures default equation.

\section{Study Areas}

The study areas were located in the north-eastern part of Hungary. The study sites comprise of three regions- the clay sample was taken at the campus of the University of Miskolc ( $\left.48^{\circ} 4^{\prime} 39.20^{\prime \prime} \mathrm{N}, 20^{\circ} 45^{\prime} 48.83^{\prime \prime} \mathrm{E}\right)$, the loam one was from the outskirt of the town of Tiszavásvari, and the sand sample was from the vicinity of the Görömböly; a district in the city of Miskolc ( $48^{\circ} 2^{\prime} 56.34^{\prime \prime}$ N, $20^{\circ} 45^{\prime} 50.93^{\prime \prime}$ E) (Figure 1). 

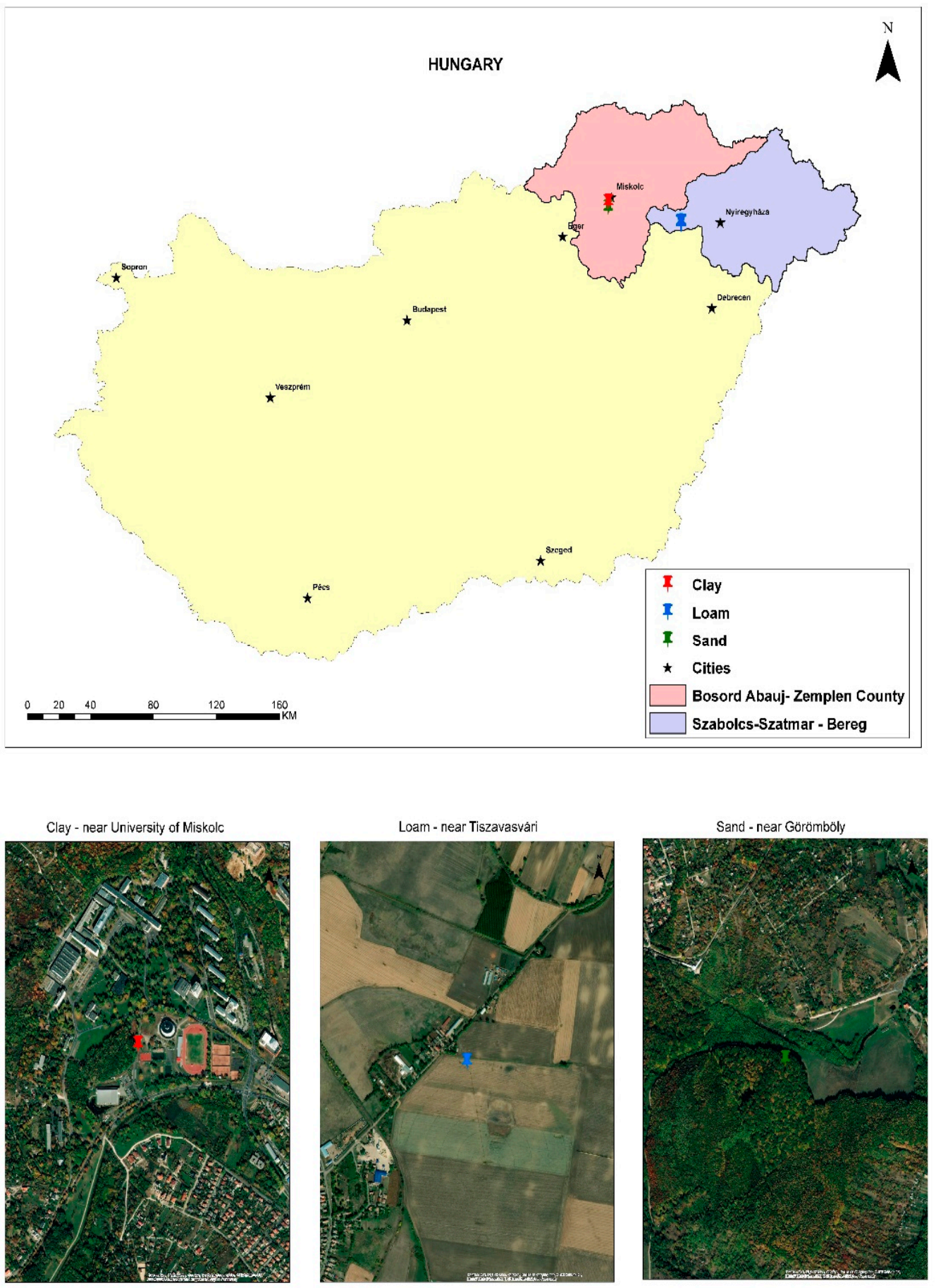

Figure 1. The locations of the study areas within Hungary.

\section{Materials and Methods}

\subsection{Materials}

\subsubsection{Soil Texture}

Three soil textures were used as a medium for calibration (Table 2). The clay sample (0-30 cm bgl) comprises black to brownish-black loose, granular-crumbly clay. The loam sample (0-30 cm bgl) comprised of dark-greyish-brown to black - soft crumbly material. The sand sample comprised of loamy sand $(0-30 \mathrm{~cm} \mathrm{bgl})$ of dull yellowish-brown, finely arranged material. 
Table 2. Soil texture of sand, loam, and clay.

\begin{tabular}{|c|c|c|c|c|c|c|c|c|c|}
\hline \multirow{2}{*}{ Soil Texture } & \multirow{2}{*}{ Depth (cm) } & \multicolumn{3}{|c|}{ Sand } & \multicolumn{3}{|c|}{ Silt } & \multirow{2}{*}{$\begin{array}{c}\text { Clay } \\
<0.002\end{array}$} & \multirow{2}{*}{ Soil Textural Class * } \\
\hline & & $>0.25$ & $0.25-0.05$ & $0.05-0.02$ & $0.02-0.01$ & $0.01-0.005$ & $0.005-0.002$ & & \\
\hline Clay & $0-30$ & 2.99 & 0.38 & 17.5 & 4.69 & 6.87 & 5.78 & 61.8 & Clay \\
\hline Loam & $0-30$ & 0.78 & 6.54 & 25.4 & 25.9 & 6.98 & 10.3 & 24.2 & Loam \\
\hline Sand & $0-30$ & 34.10 & 27.04 & 17.21 & 7.48 & 4.34 & 3.60 & 6.23 & Loamy Sand \\
\hline
\end{tabular}

\subsubsection{Instrument-EnviroScan Sensor}

The EnviroScan sensor consists of multiple sensors installed on an extruded plastic framework placed at intervals of $10 \mathrm{~cm}$ along its length (Figure 2). The sensor consists of two brass rings mounted on a plastic sensor body separated by a $12 \mathrm{~mm}$ plastic ring $[13,20]$. The conductive rings of the sensor form the plates of the capacitor. This capacitor is connected to an LC oscillator consisting of an inductor (L) and a capacitor (C) connected to circuitry that oscillates at a frequency depending on the values of $L$ and $C$ [20]. As the inductor is fixed (seven turns of $0.5-\mathrm{mm}$ wire), the frequency of oscillation varies depending on variations in the capacitance. The oscillating capacitance field generated between the two rings of the sensor extends beyond the polyvinyl chloride (PVC) access pipe into the surrounding medium. The sensor measures the oscillation frequency of the sensor's capacitance field and extending into the surrounding medium. A data logger connected to the sensor records output counts proportional to the frequency of oscillation, which is, in turn, proportional to the capacitance of the soil being sampled [16]. The EnviroScan sensor determines soil water content through a scaled count [34]. Counts were recorded for each sensor inside an access tube suspended in the air. The second set of counts were recorded for each sensor inside a sealed container of water. This was done to determine the full scale of counts between no water (air) and 100\% water [34]. The scaled count for a given sensor can be considered a percentage of full scale where the difference between air count (no less water) and the measurement count is divided full scale of counts for the sensor. Dane and Topp [35] list the positive features of capacitance probes as robust and stable instrumentation, fast response times, accuracy with good soil-probe contact, ease of use, safety, availability in several sensor configurations, and ability to be linked to an automatic data logger. However, for a capacitance probe to function correctly, there must be good contact between the access tube and the surrounding soil materials [36]. de Rosny et al. [37] and Scobie et al. [38] also found that the capacitance probe's sensitivity to soil moisture was significantly reduced when good contact between the access tube and surrounding soil is not maintained.

Two of the EnviroScan sensor limitations could be the normalization of the EnviroScan sensor and the selection of distance to take a sample adjacent to the sensor, i.e., the sphere of influence. Firstly, normalization is the process of obtaining measurements in water and air to enable the comparison of raw count readings between different probes. In this study, Sentek Solo using Probe Configuration Utility (PConfig) and a Normalization container were used. The normalization process involves setting the effective range over which the EnviroScan sensors work. These limits are set between air and water, with the sensor located in the appropriately sized access tube. Without accurate EnviroScan sensor normalization, the final calibration equation would be inaccurate. Therefore, since one sensor was used for both field and laboratory calibrations, the normalization process was completed once. However, if multiple sensors were used, the procedure would differ. Thus, to ensure consistent data, the probe would be renormalized using the same environment and normalization container as the original normalization. Secondly, the Sphere of Influence (SOI) of the EnviroScan, EasyAG, and Diviner 2000 sensors is assumed to extend radially to $14 \mathrm{~cm}$ from the access tube's surface [23]. Axially, the SOI can be assumed to extend $5 \mathrm{~cm}$ above and $5 \mathrm{~cm}$ below the mid-point between the two constituent brass rings of the capacitance sensor. The sphere of influence, or region of soil measured by the probes, is much smaller for capacitance sensors $(10 \mathrm{~cm})$ than for the neutron-emitting 
source $(15-25 \mathrm{~cm})$ [39]. The larger the sphere of influence, the higher the level of sensitivity and accuracy, and a better representation of soil water content, but a smaller sphere size with increased water contents changes the sample size and decreases accuracy in saturated soils [23]. Therefore, careful attention was given in both field and laboratory calibrations to reduce the sphere influence's effect during the collection of soil samples used for gravimetric measurements.

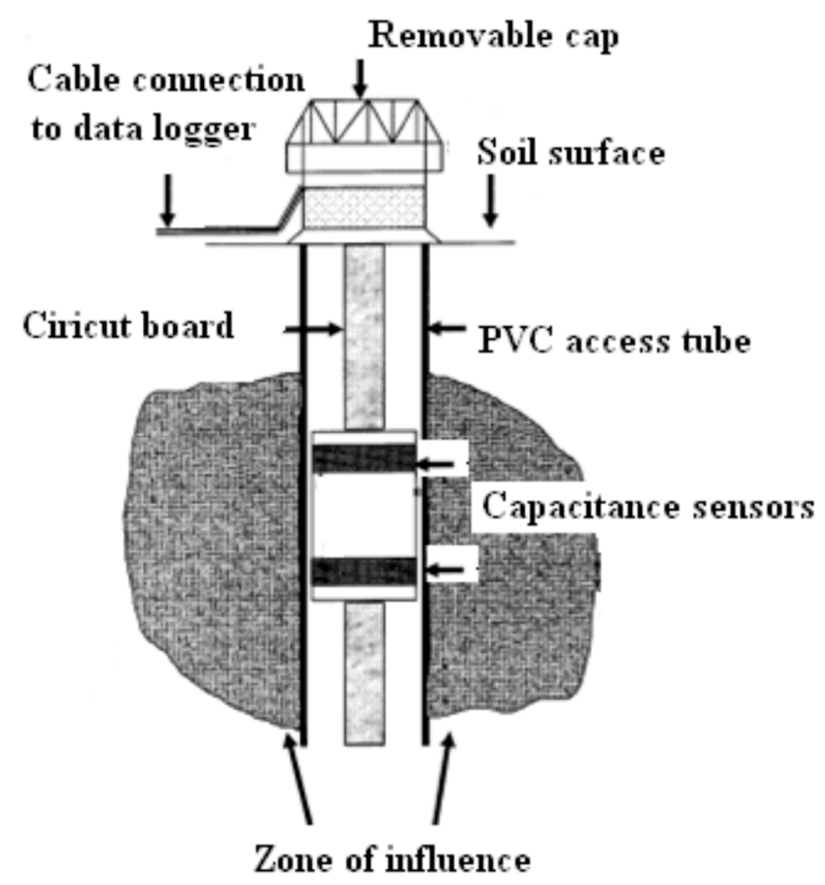

Figure 2. EnviroScan capacitance sensor as installed in a PVC access tube in the field [11].

3.2. Methods

\subsubsection{Gravimetric Method}

Undisturbed soil samples were taken from field and laboratory measurements. The samples were placed in closed rings and transported to the laboratory for measurement and processing. Measurements were started immediately after the sampling to avoid any loss of soil moisture by accidental drying.

A well-known, direct and accurate method for measuring soil water content is the gravimetric method by which soil samples are weighed before and after oven-drying, thereby determining the weight loss of water per unit of soil mass or soil volume [39,40]. The samples were weighed to get a "Total wet" sample reading $\left(\mathrm{M}_{\mathrm{w}}\right)$ and dried for $24 \mathrm{~h}$ at $105^{\circ} \mathrm{C}$ to remove all water in the soil. Once the drying was complete, the sample was then weighed again, and a "Total dry" sample $\left(\mathrm{M}_{\mathrm{d}}\right)$ measurement was taken. The dried soil was then removed from the metallic ring $(R)$, and the ring was weighed as well. After this, the "Total wet" soil measurement was subtracted from the ring's measured weight to get the actual wet soil measurement; the same was done for the dry soil. Finally, the wet $\left(\mathrm{W}_{\mathrm{w}}\right)$ soil was subtracted from the dry $\left(\mathrm{W}_{\mathrm{d}}\right)$ soil to get volumetric water content in $V / V \%$. As there were replicate samples per depth, an average was calculated.

$$
\begin{gathered}
W_{w}=M_{w}-R \\
W_{d}=M_{d}-R \\
\theta_{v}=W_{w}-W_{d}
\end{gathered}
$$

whereby $\mathrm{W}_{\mathrm{w}}=$ Wet soil measurement; $\mathrm{W}_{\mathrm{d}}=$ Dry soil measurement; $\mathrm{M}_{\mathrm{w}}=$ Total wet measurement; $\mathrm{M}_{\mathrm{d}}=$ Total dry measurement; $\mathrm{R}=$ Ring; $\theta_{\mathrm{v}}=$ Volumetric Water Content. 
$1 \mathrm{~g} / \mathrm{cm}^{3}$ density of the water was assumed, so the weight in grams was directly converted to $\mathrm{cm}^{3}$. The ring's total volume was $100 \mathrm{~cm}^{3}$, so the amount of water in $\mathrm{cm}^{3}$ was equal to the volumetric percentage.

\subsubsection{Calibration Procedure}

The General Framework of the Calibration Procedure

The framework used for the calibration procedure was split into two major steps:

In step 1: The calibration exercise started with a field experiment, where three sites with different textures were selected, and Sentek calibration measurements were done nine times between March and June 2020 to cover a relatively wide range of soil moisture (SM) conditions. This could be considered a short study duration; however, the objective was to test the calibration under different seasonal, temporal moisture patterns throughout the plant's growing life. Each time, undisturbed samples were taken from the neighborhood for gravimetric SM measurements to characterize the sensor performance using its default manufacturers equation and select the best built-in equation to maximize the performance. In the end, regression analysis was performed to develop the soil-specific estimation equations.

In step 2: The field exercise did not provide wide enough coverage of the potential SM ranges. Therefore, complementary measurements after field wetting of the sandy soil and laboratory measurements for loam and clay soils were performed. It provided one extrafully saturated-repetition for the sand field measurement-extending the soil moisture condition to the most extreme saturated state. Similar field wetting would have been very slow and insufficient for the other two texture classes, so laboratory measurements with continuous wetting and mixing were decided. Several measurements of different wetness conditions for loam and clay textures were performed. Unfortunately, the soil conditions are changed compared to the field exercise; therefore, field and laboratory measurements were kept and used separately for the statistical analysis.

\section{Step 1-Field calibration}

Field calibration was split into two phases; in phase one, field calibration took place between March and June 2020. During this period, nine measurement campaigns were carried out, with the initial aim of selecting calibrated equations specific to different textures of soil. This comprised processing and selecting the best-fit calibration equation from an array of sixty-nine built-in EnviroScan sensor equations. During March, the first four measurement campaigns were carried out to observe the change in season from Winter to Spring, where the soil water status was changing. The second campaign was accomplished during the middle of Spring, once temperatures started to rise and soil water content decreased due to evapotranspiration. The third campaign was completed during the summer season, characterized by hot and humid temperatures and even lower soil water content. The nine corresponding dates are indicated in Table 3.

Three different sites with sand, loam, and clay textures were selected for the fieldwork. During all nine repetitions, one EnviroScan sensor access pipe was installed at each site. The same sensor array with three sensors at the depths of $0-10 \mathrm{~cm}, 10-20 \mathrm{~cm}$, and 20-30 cm-was used for all sites, using it as a portable device placed into the access tube at the time of reading and sampling. Access tubes were installed with the specific kit. A tripod with a vertical leveling capability was anchored to the ground and held the PVC access pipes in an upright position. Simultaneously, a soil auger was inserted through the pipe to remove the soil inside the tube and deepen the hole for easier cut by the pipe. The PVC tube was then pushed down into the hole, and the process was continued until a depth of $60 \mathrm{~cm}$ was reached. After cleaning the inside of the PVC tube, a compression rubber plug was inserted to seal the pipe's bottom against water and vapor. The male-threaded section of PVC, which was used to receive the probe's removable screw cap, was then sealed with silicone glue to the top of the pipe. This installation was done to reduce soil disturbance during installation and ensure perfect contact between the soil and tube to avoid air gaps and preferential water flows [40]. 
Table 3. Volumetric water content from Gravimetric method.

\begin{tabular}{|c|c|c|c|c|c|c|c|c|c|c|c|c|c|c|c|c|c|c|c|}
\hline \multirow[b]{2}{*}{$\begin{array}{l}\text { Soil } \\
\text { Type }\end{array}$} & \multirow[b]{2}{*}{$\begin{array}{c}\text { Depth } \\
\text { (cm) }\end{array}$} & \multicolumn{2}{|c|}{ 11-March } & \multicolumn{2}{|c|}{ 16-March } & \multicolumn{2}{|c|}{ 25-March } & \multicolumn{2}{|c|}{ 31-March } & \multicolumn{2}{|c|}{ 08-April } & \multicolumn{2}{|c|}{ 15-April } & \multicolumn{2}{|c|}{ 06-May } & \multicolumn{2}{|c|}{ 18-June } & \multicolumn{2}{|c|}{ 24-June } \\
\hline & & $\begin{array}{c}\text { Moisture } \\
{[v / v \%]}\end{array}$ & Avg & $\begin{array}{c}\text { Moisture } \\
{[v / v \%]}\end{array}$ & Avg & $\begin{array}{c}\text { Moisture } \\
{[v / v \%]}\end{array}$ & Avg & $\begin{array}{c}\text { Moisture } \\
{[v / v \%]}\end{array}$ & Avg & $\begin{array}{c}\text { Moisture } \\
{[v / v \%]}\end{array}$ & Avg & $\begin{array}{c}\text { Moisture } \\
{[v / v \%]}\end{array}$ & Avg & $\begin{array}{c}\text { Moisture } \\
{[v / v \%]}\end{array}$ & Avg & $\begin{array}{c}\text { Moisture } \\
{[v / v \%]}\end{array}$ & Avg & $\begin{array}{c}\text { Moisture } \\
{[v / v \%]}\end{array}$ & Avg \\
\hline \multirow{2}{*}{ Clay } & $0-10$ & 37.13 & \multirow{2}{*}{37.27} & 41.03 & \multirow{2}{*}{40.67} & 35.92 & \multirow{2}{*}{36.61} & 32.48 & \multirow{2}{*}{33.73} & 33.96 & \multirow{2}{*}{33.93} & 25.14 & \multirow{2}{*}{25.56} & 25.46 & \multirow{2}{*}{25.16} & 29.83 & \multirow{2}{*}{30.75} & 28.56 & \multirow{2}{*}{28.66} \\
\hline & $20-30$ & 35.92 & & 40.12 & & 35.99 & & 34.18 & & 34.22 & & 25.45 & & 25 & & 32.32 & & 27.85 & \\
\hline \multirow{3}{*}{ Loam } & $0-10$ & 33.22 & \multirow{3}{*}{34.2} & 32.73 & \multirow{3}{*}{32.5} & 30.54 & \multirow{3}{*}{30.68} & 33.56 & \multirow{3}{*}{34.11} & 34.83 & \multirow{3}{*}{33.66} & 32.47 & & 30.26 & \multirow{3}{*}{29.73} & 28.87 & \multirow{3}{*}{29.53} & 34.27 & \multirow{3}{*}{33.1} \\
\hline & $10-20$ & 34.05 & & 31.47 & & 30.51 & & 34.66 & & 33.99 & & 33.27 & 33.11 & 30.41 & & 29.14 & & 32.09 & \\
\hline & $20-30$ & 35.34 & & 33.31 & & 31 & & 34.1 & & 32.15 & & 33.59 & & 28.51 & & 30.59 & & 32.93 & \\
\hline \multirow[t]{2}{*}{ Sand } & $10-20$ & 25.49 & \multirow[t]{2}{*}{24.46} & 21.58 & \multirow[t]{2}{*}{21.77} & 20.78 & \multirow[t]{2}{*}{20.23} & 18.67 & 18.3 & 19.02 & 18.69 & 18.53 & 18.23 & 18.01 & 17.36 & 12.52 & 12.7 & 11.81 & 11.29 \\
\hline & $20-30$ & 22.12 & & 21.29 & & 18.95 & & 18.1 & & 18.54 & & 19.58 & & 16.44 & & 12.97 & & 11.69 & \\
\hline
\end{tabular}


The same sensor set was used for all sites and repetitions. Initially, the sensor was calibrated by placing it in the air and into a water tank using the access pipe, and raw readings were recorded for the two extremes. The water tank measurement was repeated with saturated soil as well, but no significant change was experienced. During each measurement campaign, data was recorded for approx. 15 min per measurement campaign, in all three depths, namely 0-10 cm, 10-20 cm, and 20-30 cm. The data was then downloaded using the Sentek software and used to calculate the Scaled Frequencies, which is calculated as below:

$$
\mathrm{SF}=\left(\mathrm{F}_{\mathrm{A}}-\mathrm{F}_{\mathrm{S}}\right) /\left(\mathrm{F}_{\mathrm{A}}-\mathrm{F}_{\mathrm{W}}\right)
$$

whereby $\mathrm{SF}=$ Scaled frequency, $\mathrm{F}_{\mathrm{A}}=$ raw count suspended in air (Air Count), $\mathrm{F}_{\mathrm{W}}=$ raw count in a water bath or normalization container (Water Count), and $F_{S}=$ raw count in the PVC access tube in the soil at each particular depth level (Field Count).

These SF values were analyzed to calculate volumetric water content with the best fit curve as the water content obtained from the gravimetric method. Data from the $0-10 \mathrm{~cm}$ and 20-30 cm were used only for background information to characterize the vertical changes and the potential measurement mistakes or errors. Only the 10-20 cm depth sensor data was used for the regression exercise.

At the time of the measurements, three undisturbed soil samples were taken between 1 and $2 \mathrm{~m}$ distances from the access tube (adjacent to the PVC tube) to keep the sensors' immediate surroundings undisturbed. Samples were taken from the three corresponding depths (0-10 cm, 10-20 cm, and 20-30 cm). After collection, soil samples were immediately leveled, cleaned and sealed, and taken to the laboratory for analysis, as explained in the gravimetric method above.

\section{Step 2-Complementary measurements}

The weather conditions throughout the sensing period were less variable than we expected; no substantial precipitation occurred that could totally saturate the soils. Therefore, phase two of field and laboratory calibrations were performed in October 2020. Complementary field application was completed for the sand soil texture only due to its faster infiltration rate. The same procedure was followed as was described in phase one, except for wetting the soil. A total of $60 \mathrm{~L}$ of water was applied to the sand texture until complete saturation was reached after one hour. Soil samples were collected at depths of $0-10 \mathrm{~cm}$, $10-20 \mathrm{~cm}$, and $20-30 \mathrm{~cm}$ for gravimetric assessment. These samples were taken immediately next to the access tube because the tube was removed, and there was no need to keep the site undisturbed anymore. Finally, the recorded measurements were downloaded for analysis.

The other two soil texture types were analyzed further in the laboratory. The laboratory calibration took place using one sensor for two soil textures-clay and loam. This was done because of their slower infiltration properties as compared to sand. The height of the soil profile was $20 \mathrm{~cm}$. The capacitance sensor on the probe was placed in the middle of the soil volume. Figure 3 shows a schematic of the experimental setup and its dimensions. Both soils were air-dried for $12-48 \mathrm{~h}$ to allow excess water content to evaporate and reach the driest condition to extend the soil moisture range measurements. Once the soil had dried, it was poured and mixed homogenously in a bucket-with the EnviroScan sensor placed in the center of the bucket. To ensure there was close contact between the probe and soil, the soil was poured in uniform layers as the probe was being firmly held to ensure there would be no spaces between the soil and the outer part of the probe. However, we were careful to make sure we do not compress the soil as this would change the bulk density properties, affecting the water content. An initial measurement was then recorded as a dry sample, and then frequent wetting and mixing were done. The soil was moistened using a handheld garden sprinkler. Approximately 4-8 readings were taken per soil texture or until complete saturation of the soil was obtained. During each of the repetitions, two undisturbed soil samples were taken for gravimetric measurements. 

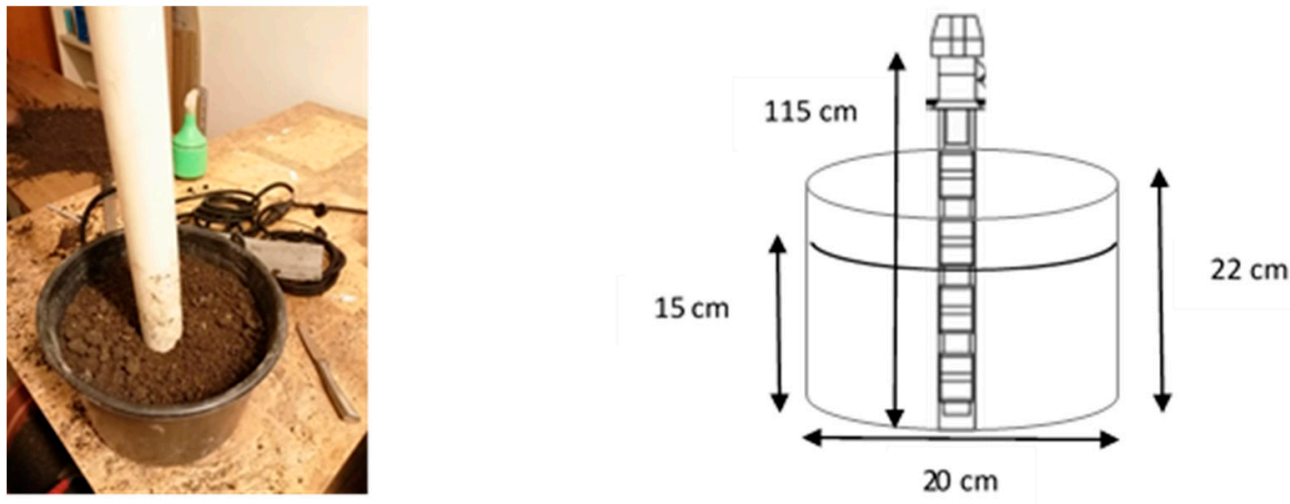

Figure 3. Schematic of the experimental laboratory setup.

Application of Equations Provided by the Sentek Manufacturer

Data was downloaded from the EnviroScan sensor via the data logger onto a CSV file for both field and laboratory calibrations. The CSV file data was used to convert raw counts obtained from the EnviroScan sensors at each particular depth level into SF values.

First, an evaluation of the EnviroScan equations was made by comparing the estimated SM values with the volumetric water content values determined gravimetrically from a location adjacent to the tube. These values were then plotted on a graph to visualize the relationship described by a mathematical equation, dependent on the graph's curve. During the first phase of the field calibration, sixty-nine calibration equations (including the default Sentek calibration equation) were tested for each soil texture to estimate soil water content. These sixty-nine equations were derived in various soil textures from mainly Australia and the United States of America [23].

\section{Statistical Analysis}

Besides using the built-in equation set, regression analysis using the SF and gravimetric volumetric content was performed on the datasets. By default, Sentek uses a power/logarithmic regression formula, where the coefficients (A, B, and C) can be entered in the EnviroScan sensor display unit of the calibration registry to derive the calibration equation. After that, the volumetric water content can be derived using the following formula [23]:

$$
\begin{gathered}
\mathrm{SF}=\mathrm{A} \theta_{\mathrm{v}}^{\mathrm{B}}+\mathrm{C} \\
\text { which is: } \theta \mathrm{v}=((\mathrm{SF}-\mathrm{C}) / \mathrm{A})^{\wedge} 1 / \mathrm{B}
\end{gathered}
$$

whereby A, B, C = Coefficients.

Linear and logarithmic regression analyses were run in this study using the scaled frequency and volumetric water content. Logarithmic regression was used to present the results for a few reasons. One, it yielded better results than linear regression, two; the curve fit of points in the upper and lower ends of the data set was better fitted for a logarithmic fit, and three; the Sentek calibration manual suggests a power/logarithmic regression formula. The statistical metrics used for analysis were the coefficient of determination $\left(\mathrm{R}^{2}\right)$ and root mean square error (RMSE). The derived regression coefficients were recorded and used in the soil-specific calibration equation.

\section{Results}

The results are presented in two sections; field calibration only and complemented with laboratory calibration setups. The field calibration comprised of two phases; phase one included all three soil textures, and phase two only sand soil texture. The sand soil texture was measured in phase 2 because phase 1 results showed a low correlation in wet conditions. Besides, it was not time-consuming due to fast infiltration during field calibration. 


\subsection{Field Calibration-Phase 1}

In this part of the work, we tested the built-in SM estimation algorithms of the Sentek sensor. The default Sentek calibration algorithm was tested first, as the most commonly used one for none soil experts. After testing the default equation, we selected the best fitting equation from the Sentek library for each texture class, regardless of their names. Finally, we grouped the algorithms based on their names, indicating the corresponding texture class, because this is what an expert would do to optimize the estimation. All algorithms that indicated "clay" in their name were used for the clay group, and the same approach was used for the loam and the sand texture classes.

\subsubsection{Sentek Default Calibration}

The field calibration setup results are presented by showing the laboratory-measured gravimetric water content results obtained in each soil texture at their corresponding depths (Table 3). The fieldwork took almost four months, starting in early spring and ended in early summer. The period was chosen as a representative time span for spring crops. This is also the period with the highest potential range of soil moisture values, close to saturation in early spring and drying out for the summer. The actual measured ranges of soil moisture values varied among the textures. Maximums and minimums for the clay, loam, and sand textures were 40.67-25.56, 34.2-29.5, and 24.46-11.29.

The recorded estimations calculated using the default Sentek calibration equation are also presented in each soil texture and depth $(0-10 \mathrm{~cm}, 10-20 \mathrm{~cm}$, and $20-30 \mathrm{~cm})$ (Table 4). These measurements were then compared to the gravimetric method measurements (Figure 4). Figure 4 shows high absolute differences between gravimetric and recorded measurements from the EnviroScan sensor for the 10-20 cm only, as this was the depth used for the calibration exercise. For clay, the sensor's first four repetitions overestimated the volumetric water content (VWC), whereas in repetitions five to nine, it underestimated the VWC. In the example of loam, the sensor overestimated VWC, whereas, in the sand, it underestimated the VWC. The three cases' interpretation indicates that the default Sentek equation overestimated the VWC for the higher VWC ranges and underestimated it for the drier soil conditions. The root mean square error (RMSE) for the clay and loam were about 15, while sand was much better, with a value of 5.77 . These values mean a $30 \%$ (for the sand) and $60-70 \%$ (clay and loam) relative difference in soil water content, thus rendering the default Sentek calibration equation not optimal for calibration and requiring soil-specific calibration equations.

Table 4. Estimated Volumetric water content using the default Sentek calibration algorithm (Field Calibration-Phase 1).

\begin{tabular}{|c|c|c|c|c|c|c|c|c|c|c|}
\hline & \multicolumn{2}{|c|}{ 11-March } & 16-March & 25-March & 31-March & 8-April & 15-April & 6-May & 18-June & 24-June \\
\hline Soil Type & Depth & \multicolumn{9}{|c|}{ EnviroScan Estimations } \\
\hline \multirow{3}{*}{ Clay } & $0-10$ & 34.81 & 30.8 & 23.58 & 15.17 & 5.4 & 4.95 & 1.23 & 5.55 & 18.85 \\
\hline & 10-20 & 44.78 & 44.84 & 44.26 & 42.69 & 29.32 & 12.27 & 3.54 & 7.38 & 11.89 \\
\hline & $20-30$ & 40.76 & 42.71 & 45.17 & 43.13 & 45.16 & 34.99 & 6.94 & 19.35 & 6.01 \\
\hline \multirow{3}{*}{ Loam } & $0-10$ & 33.72 & 35.46 & 33.27 & 34.98 & 24.4 & 23.07 & 12.19 & 31.77 & 33.9 \\
\hline & 10-20 & 52.11 & 51.65 & 51.54 & 51.75 & 53.28 & 52.06 & 41.61 & 47.76 & 47.39 \\
\hline & $20-30$ & 49.09 & 49.87 & 46.8 & 49.38 & 47.56 & 49.61 & 33.73 & 39.5 & 39.29 \\
\hline \multirow{3}{*}{ Sand } & $0-10$ & 12.37 & 12.43 & 12.21 & 11.52 & 11.48 & 11.46 & 11.96 & 8.72 & 7.23 \\
\hline & 10-20 & 14.38 & 13.97 & 14.07 & 13.57 & 13.2 & 13.2 & 14.16 & 10.35 & 8.86 \\
\hline & $20-30$ & 12.37 & 13.17 & 12.93 & 13.06 & 12.62 & 12.52 & 14.74 & 10.8 & 9.23 \\
\hline
\end{tabular}




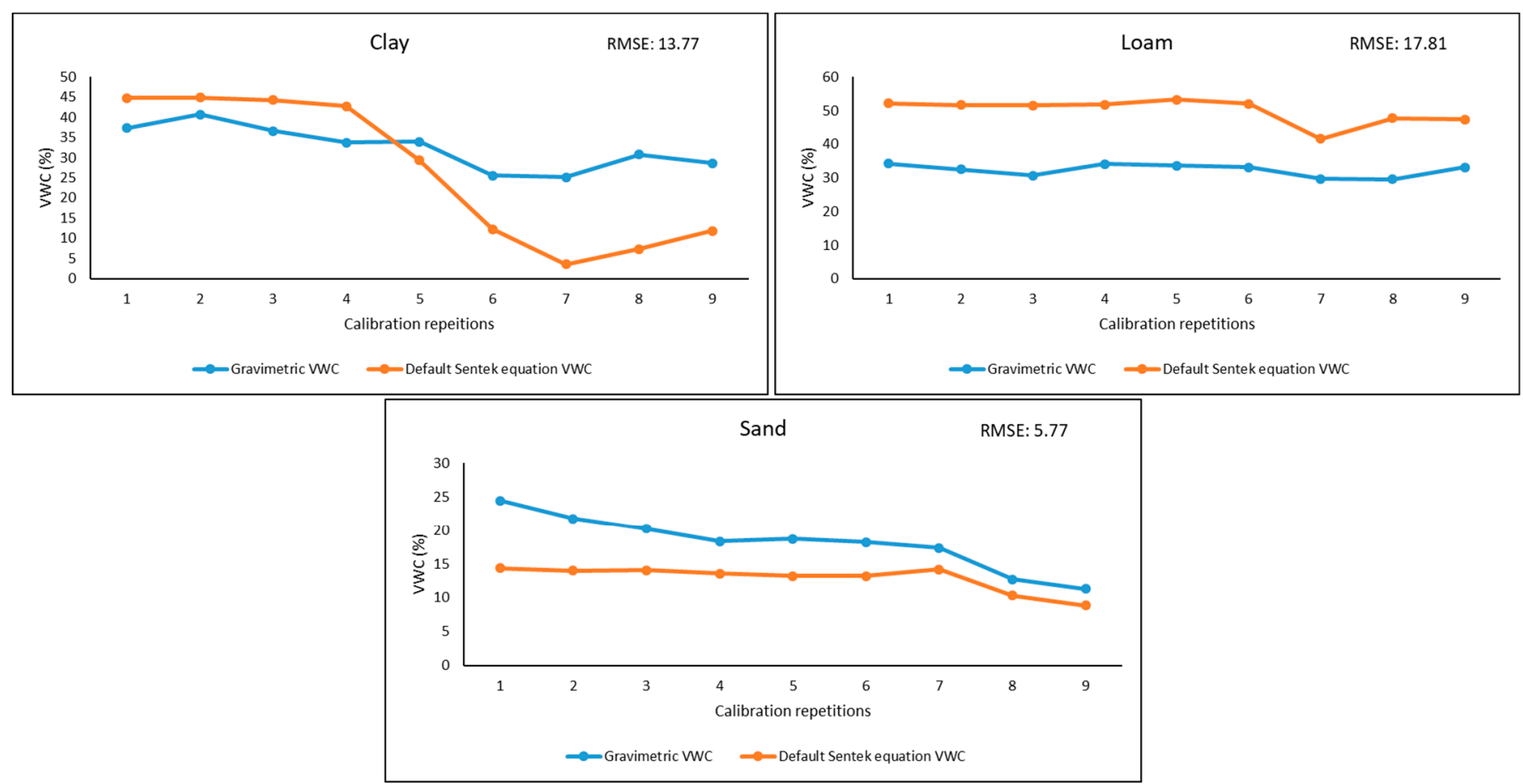

Figure 4. Gravimetric VWC (blue line) compared to VWC derived from default Sentek calibration equation (orange lines) for the nine dates.

\subsubsection{Best-Fitting Equation from the Manufacturer's Library}

The EnviroScan has sixty-nine built-in soil-specific calibration equations. All of them were run on our field dataset to choose the best fitting algorithm. Figure 5 shows significant correlation improvements in all classes. The RMSE values have decreased significantly in all three texture classes; the average deviance from the laboratory data ranged between 2 and 3.5, which are quite acceptable for any field measurement. The best-fitting algorithms were always the ones referring to the texture class in question.

4.1.3. Best-Fitting Equations from the Manufacturer's Library with the Indication of Texture

Soil experts-understanding the importance of soil property-specific estimation algorithms-would choose the algorithms according to the texture class indication in the naming. In this phase of the study, soil texture-specific calibration equations-indicating the corresponding texture class in the name of the algorithm-were selected and tested to identify the best-fit calibration equations for each soil type. Figure 6 presents the best three fits for each of the three soil textures. The most consistent performances of the available equations were found for the sand soil texture class, where all the best three options were found to have an RMSE value around 2-2.5. Similarly, well-distributed RMSE values were found for the clay category; however, the overall performance was less accurate. The worst results were found for the loam class with RMSE values ranging between 2 to 9, and only one equation had acceptable performance. The second best RMSE was 6.3, which is already exceeds 10 relative percent of the potential full range of values. 


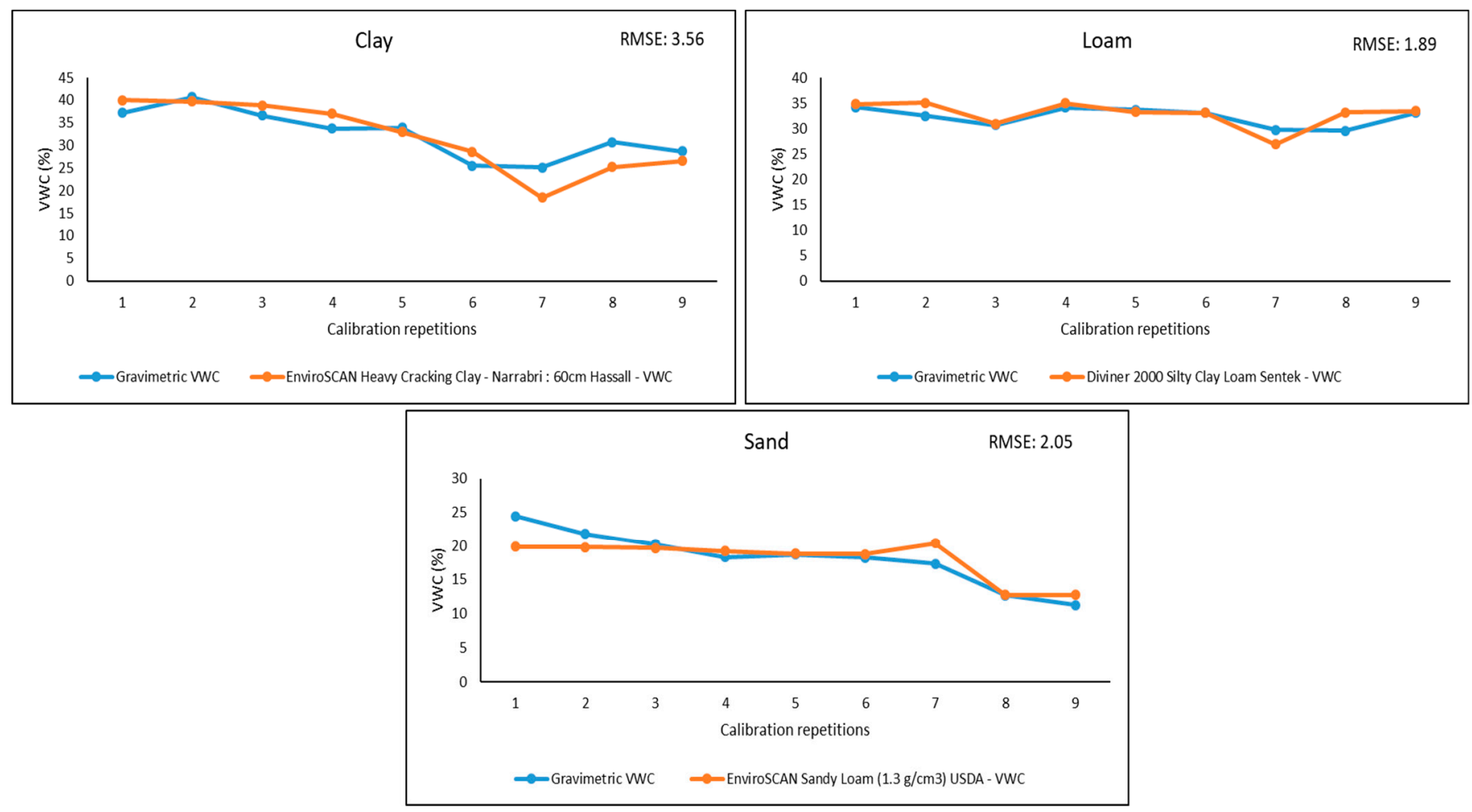

Figure 5. Gravimetric VWC (blue line) compared to calculated VWC using the best fitting equations (orange lines) of EnviroScan sensor.

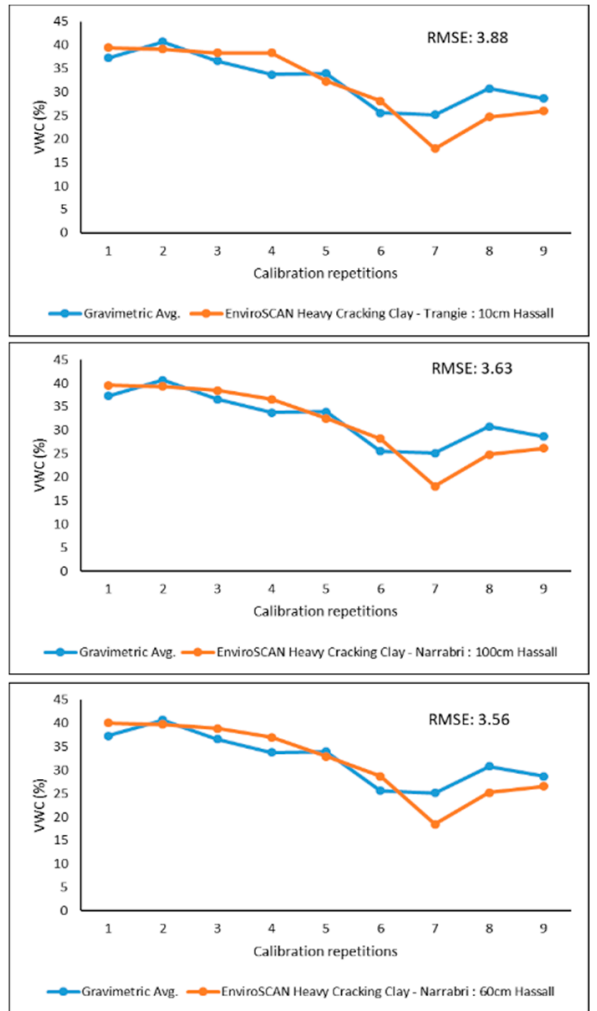

(a)
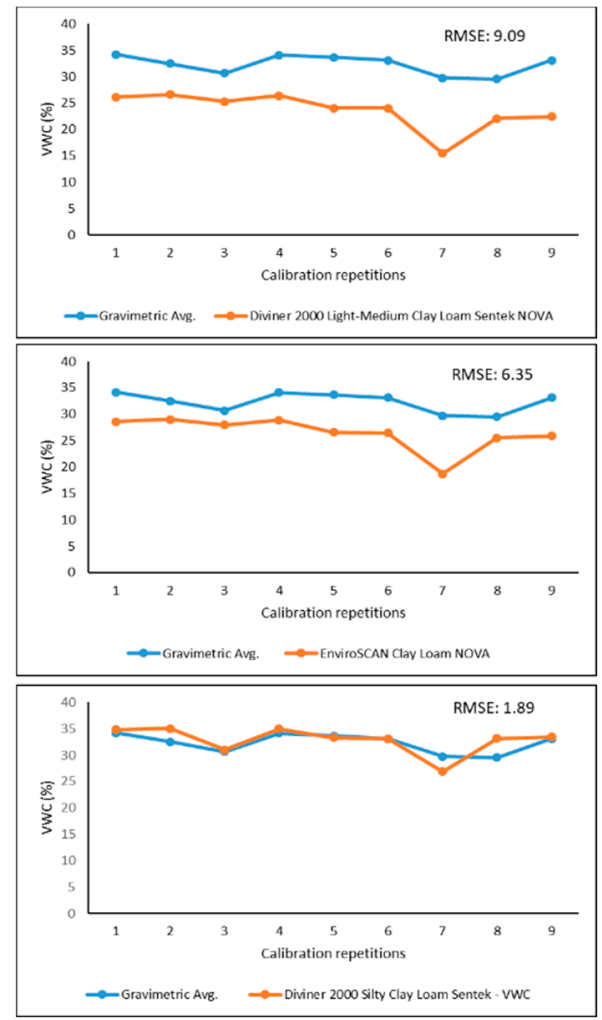

(b)

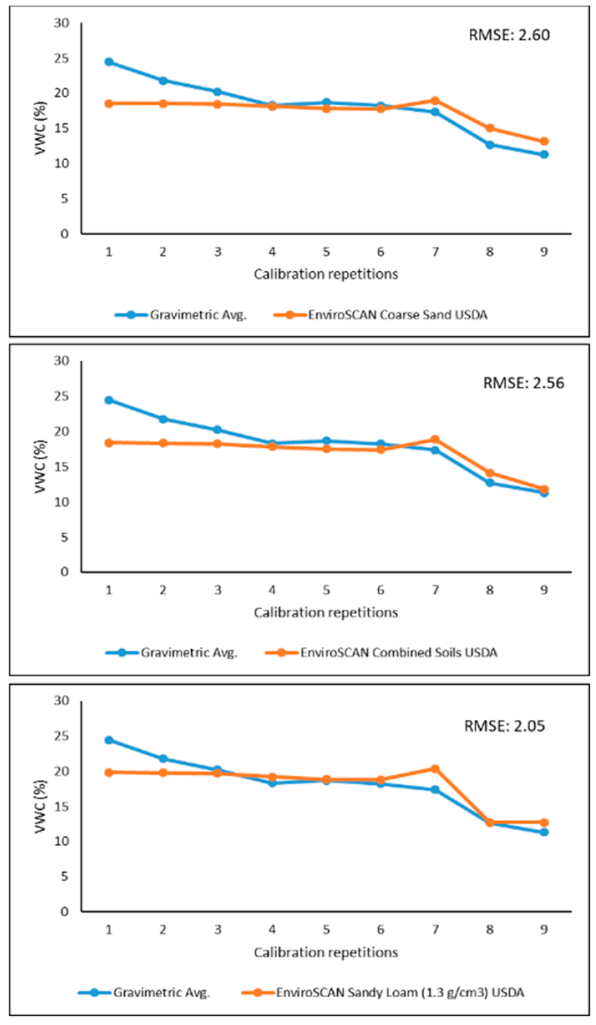

(c)

Figure 6. Gravimetric VWC (blue line) compared with the three best fit soil-specific EnviroScan calibration equations (orange lines) indicating the corresponding texture class: (a) clay; (b) loam; (c) sand. 


\subsubsection{Regression Results}

Regression analysis was performed for all three datasets using the average volumetric water content of the three depths and the scaled counts of the 10-20 cm depth sensor. Several kinds of regression models were tested. The linear model performed well, but the best fits were achieved using logarithmic regression models for each soil texture. This meets with the manufacturer's suggestion because the SF value change for a unit of SM change is decreasing toward the wet part following a logarithmic relationship. The statistics are given in Table 5.

The coefficient of determination $\left(R^{2}\right)$ values for the three soil textures were relatively significant with clay -0.79 and sand -0.83 , whereas for loam -0.40 , it was less significant (Figure 7). The RMSE values were almost in the same range for all texture classes as of the default Sentek equation results, meaning that phase one of field calibration did not improve the correlation, and as such further measurements were required. The $p$ values for clay (0.001) and sand (0.003) textures showed statistical significance $(p \leq 0.05)$. In contrast, the loam $(0.07)$ texture was not statistically $(p>0.05)$ significant. This weak performance was probably due to the small range of measured SM (namely $5 \%$ absolute) values. The measured values were between 34.2 and 29.5, representing a very small range of potential values. The potential measurement errors were probably close to the measured range of values, explaining the low performance. The clay and sand classes had much wider ranges, around $15 \%$ (Table 3 ).

Table 5. Statistical metrics associated with coefficients of various calibration equations (Field calibration-Phase 1).

\begin{tabular}{|c|c|c|c|c|c|c|c|}
\hline Soil Type & Calibration Name & Coefficient A & Coefficient B & Coefficient C & $\mathbf{R}^{2}$ & $p$-Value & RMSE (\%) \\
\hline \multirow[t]{2}{*}{ Clay } & $\begin{array}{c}\text { Clay-Heavy } \\
\text { Cracking Clay, Narrabri } 60 \mathrm{~cm}\end{array}$ & 0.0254 & 1 & -0.119 & $(0.58)$ & - & 3.56 \\
\hline & Regression results & 0.0361 & 1 & -0.4243 & 0.79 & 0.001 & 13.74 \\
\hline \multirow[t]{2}{*}{ Loam } & $\begin{array}{l}\text { Diviner } 2000 \text { Silty Clam } \\
\text { Loam Sentek }\end{array}$ & \multicolumn{4}{|c|}{ No data is given by the manufacturer } & - & 1.89 \\
\hline & Regression results & 0.0165 & 1 & -0.3955 & 0.40 & 0.07 & 14.01 \\
\hline \multirow{2}{*}{ Sand } & $\begin{array}{l}\text { EnviroScan Sandy Loam } \\
\left(1.3 \mathrm{~g} / \mathrm{cm}^{3}\right) \text { USDA }\end{array}$ & 0.013 & 1 & 0.326 & $(0.97)$ & - & 2.05 \\
\hline & Regression results (Phase 1 ) & 0.0069 & 1 & 0.4872 & 0.84 & 0.003 & 5.82 \\
\hline
\end{tabular}

$\mathrm{R}^{2}$ values in brackets are taken from the manufacturer's records.

\subsection{Field Calibration Complemented with Artificial Wetting of the Site (Sand Only)—Phase 2}

Due to the unsatisfactory results during phase one of field calibration, additional methods needed to be applied to improve the estimation performance. The laboratory SM values represented a limited range only, where the magnitude of the deviation from the estimated value was comparable with the measured SM range. The scatterplots-especially for the loam class-were quite scattered, so we decided to extend the range toward the extreme values by saturating the soil. The sand was selected as the only soil texture for field calibration, whereas clay and loam were analyzed using a laboratory calibration procedure. The sand was wetted using $60 \mathrm{~L}$ of water until saturation was reached. Bulk samples were taken from this saturated stage and analyzed in the laboratory. The results show an improved fit between the derived soil-specific equation and the gravimetric VWC (Figure 8). 


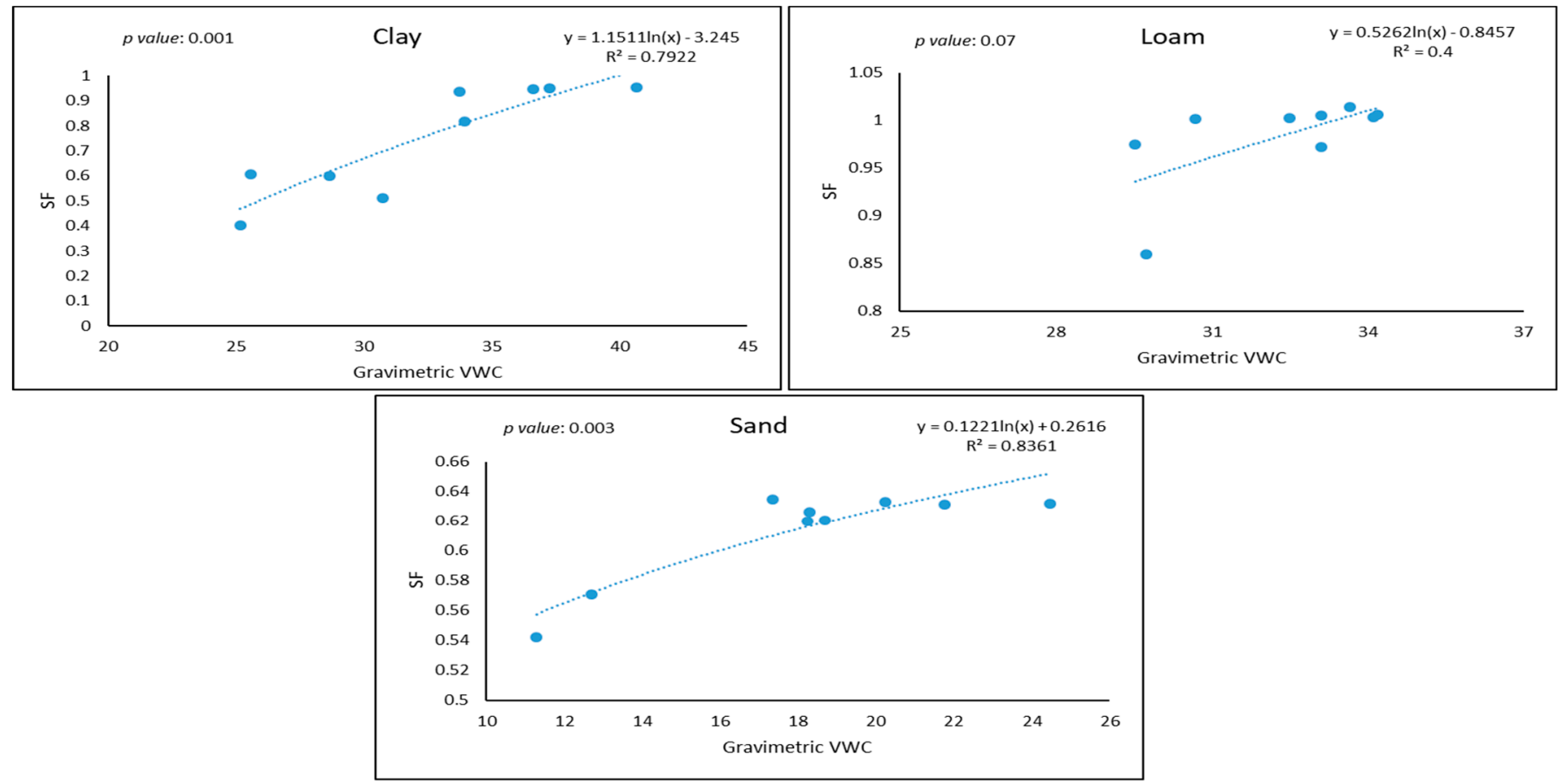

Figure 7. Fitting regression analysis of phase one field calibration.

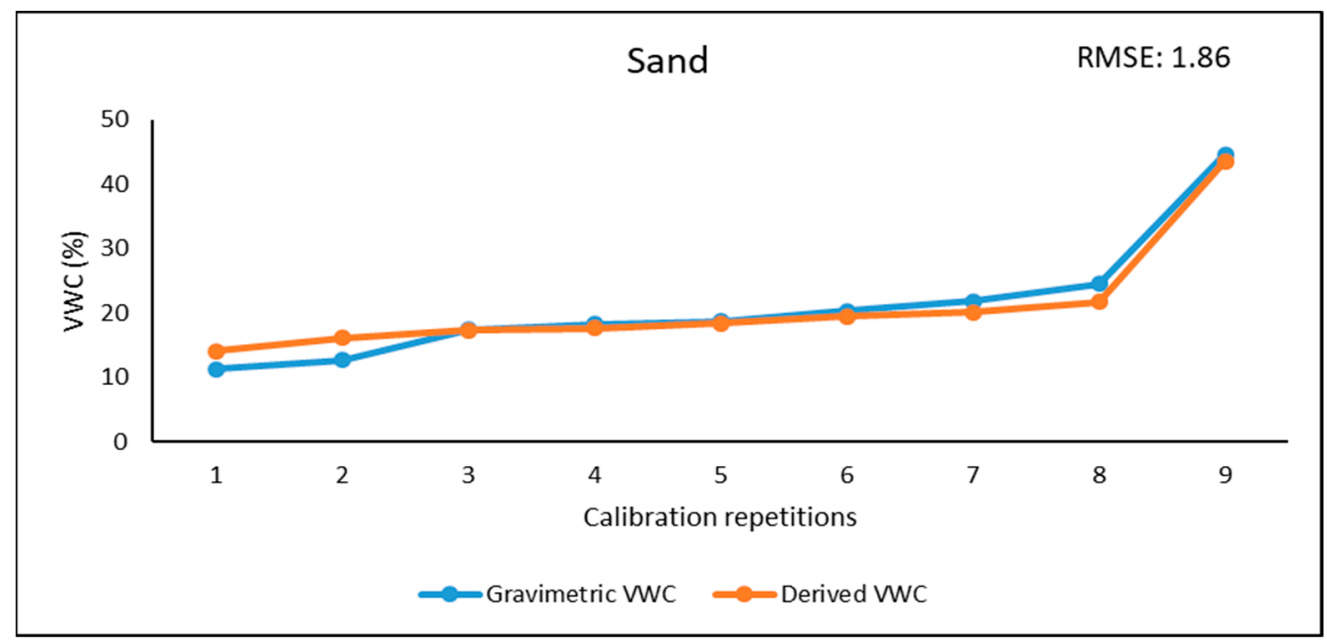

Figure 8. Sand Gravimetric VWC compared with derived VWC.

A logarithmic regression model was run on the extended database between the scaled frequencies from the EnviroScan sensors and the gravimetric VWC. This one extra observation was very significant and resulted in an $\mathrm{R}^{2}$ value of 0.91 (Figure 9 \& Table 6). This showed that catering for extreme soil conditions from moderately to very wet sandy soil improved the range and the correlation between SF and gravimetric VWC. As in phase 1 of field calibrations, the $p$-value of sand $\left(1.25 \times 10^{-8}\right)$ texture was statistically significant $(p \leq 0.05)$. 


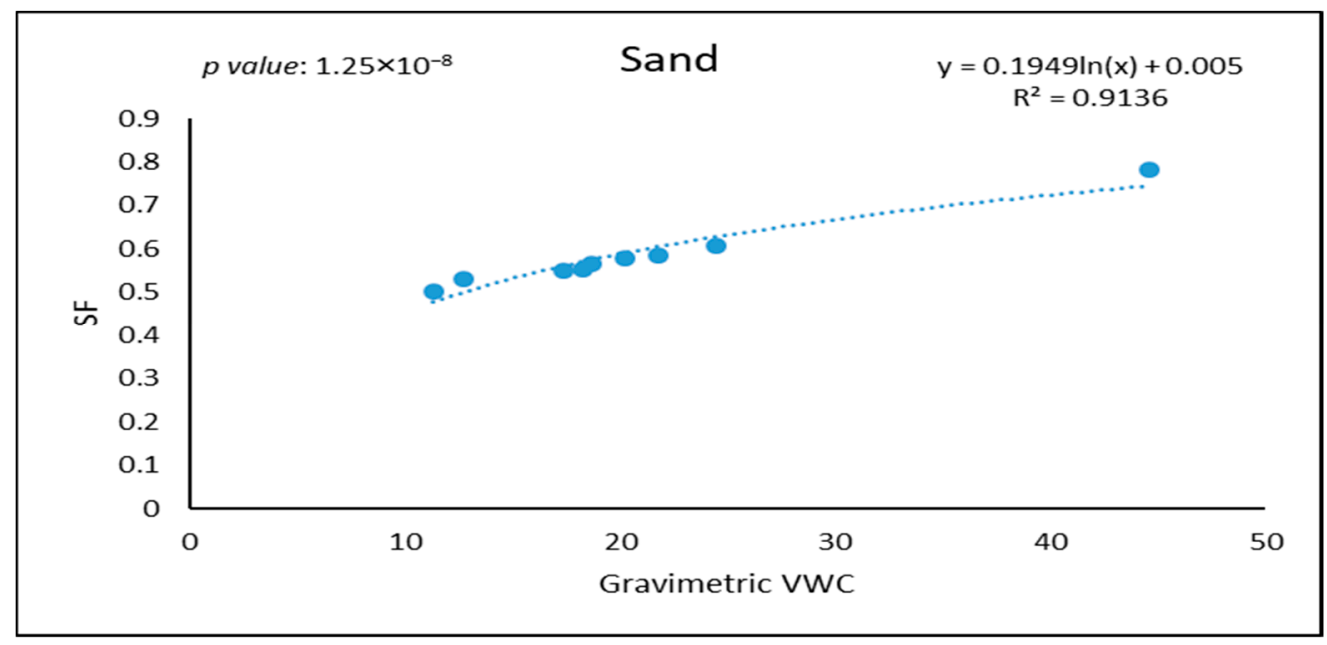

Figure 9. Fitting regression analysis of phase two field calibration.

Table 6. Statistical metrics for the Phase 2 sand calibration.

\begin{tabular}{cccccccc}
\hline Soil Type & Calibration Name & Coefficient A & Coefficient B & Coefficient C & $\mathbf{R}^{\mathbf{2}}$ & $p$-Value & RMSE (\%) \\
\hline Sand & $\begin{array}{c}\text { Calibration-Sand } \\
\text { (Phase 2) }\end{array}$ & 0.082 & 1 & 0.4106 & 0.91 & $1.25 \times 10^{-8}$ & 1.86 \\
\hline
\end{tabular}

\subsection{Laboratory Calibration}

Laboratory calibration was conducted on clay and loam soil textures due to their slower infiltration capacities. As in phase one of field calibration, the first step was to measure and retrieve gravimetric water content. Tables 7 and 8 show the gravimetric results of the laboratory calibration phase. The samples were collected at a single depth due to the bucket's size. Two samples were collected per repetition to allow for better representativity of the soil. The soils were air-dried for $12-48 \mathrm{~h}$. to widen the range of wetness conditions. Then, soils were wetted using a handheld spray sprinkler and mixed, homogenized continuously. A series of measurements and sampling were executed in the different soil moisture conditions until complete saturation was reached. Loam (Table 8) was analyzed in two batches to measure different soil properties-the first batch comprised measuring original soil and wetting. The second batch included air drying, bucket drying in a semi-closed environment.

The results show a better fit in both clay and loam soil textures (Figure 10). This is suggestive that due to the full spectrum of moisture conditions being analyzed, the correlation was strong, resulting in a good estimated VWC and an almost perfect fit between gravimetric VWC and estimated VWC for both clay and loam. In contrast to the field measurement, where samples were taken at least from $1 \mathrm{~m}$ far from the sensor to avoid disturbance, here the sampling was done right next to the tube, which explains the almost "perfect" fit of the regression. 
Table 7. Clay Laboratory calibration-Volumetric water content from Gravimetric method.

\begin{tabular}{|c|c|c|c|c|c|c|c|c|c|c|}
\hline \multicolumn{11}{|c|}{ November-20 } \\
\hline & & Original & Wetting 1 & Wetting 2 & Wetting 3 & Wetting 4 & Wetting 5 & Air Drying $12 \mathrm{~h}$ & Air Drying $24 \mathrm{~h}$ & Air Drying $48 \mathrm{~h}$ \\
\hline Soil Texture & Depth (cm) & $\begin{array}{c}\text { Moisture } \\
{[v / v \%]}\end{array}$ & $\begin{array}{c}\text { Moisture } \\
{[v / v \%]}\end{array}$ & $\begin{array}{c}\text { Moisture } \\
{[v / v \%]}\end{array}$ & $\begin{array}{c}\text { Moisture } \\
{[v / v \%]}\end{array}$ & $\begin{array}{c}\text { Moisture } \\
{[v / v \%]}\end{array}$ & $\begin{array}{c}\text { Moisture } \\
{[v / v \%]}\end{array}$ & $\begin{array}{c}\text { Moisture } \\
{[v / v \%]}\end{array}$ & $\begin{array}{c}\text { Moisture } \\
{[v / v \%]}\end{array}$ & $\begin{array}{c}\text { Moisture } \\
{[v / v \%]}\end{array}$ \\
\hline Clay & 30 & 29.21 & 32.06 & 41.47 & 50.05 & 48.1 & 57.88 & 22.61 & 20.01 & 12.61 \\
\hline
\end{tabular}

Table 8. Loam Laboratory calibration-Volumetric water content from Gravimetric method.

\begin{tabular}{|c|c|c|c|c|c|c|c|c|c|c|c|}
\hline \multicolumn{6}{|c|}{ November-20 } & \multicolumn{6}{|c|}{ December-20 } \\
\hline \multicolumn{6}{|c|}{ First Batch } & \multicolumn{6}{|c|}{ Second Batch } \\
\hline & & Original & Wetting 1 & Wetting 2 & Wetting 3 & Wetting 4 & Wetting 5 & Wetting 6 & Wetting 7 & Bucket Drying $12 \mathrm{~h}$ & Air Drying $48 \mathrm{~h}$ \\
\hline Soil Texture & $\begin{array}{c}\text { Depth } \\
\text { (cm) }\end{array}$ & $\begin{array}{c}\text { Moisture } \\
{[v / v \%]}\end{array}$ & $\begin{array}{c}\text { Moisture } \\
{[v / v \%]}\end{array}$ & $\begin{array}{c}\text { Moisture } \\
{[\mathrm{v} / \%]}\end{array}$ & $\begin{array}{c}\text { Moisture } \\
{[\mathrm{v} / \%]}\end{array}$ & $\begin{array}{c}\text { Moisture } \\
{[v / v \%]}\end{array}$ & $\begin{array}{c}\text { Moisture } \\
{[v / v \%]}\end{array}$ & $\begin{array}{c}\text { Moisture } \\
{[v / v \%]}\end{array}$ & $\begin{array}{c}\text { Moisture } \\
{[v / v \%]}\end{array}$ & Moisture $[v / v \%]$ & Moisture $[v / v \%$ \\
\hline Loam & 30 & 30.13 & 39.58 & 38.83 & 41.07 & 30.13 & 28.83 & 41.79 & 37.86 & 24.52 & 7.92 \\
\hline
\end{tabular}


The regression results for both clay and loam recorded an $\mathrm{R}^{2}$ value of 0.92 and 0.83 and a root mean square error (RMSE) of 3.85 and 2.27, respectively (Table 9 and Figure 11). The $\mathrm{R}^{2}$ values showed a little bit of an increase, but the RMSE has not been improved compared to the best fitting manufacturer's equations. The $p$-value for clay texture remained significant, just like in the results field calibration-phase 1, whereas the loam texture results changed from non-significant to significant.
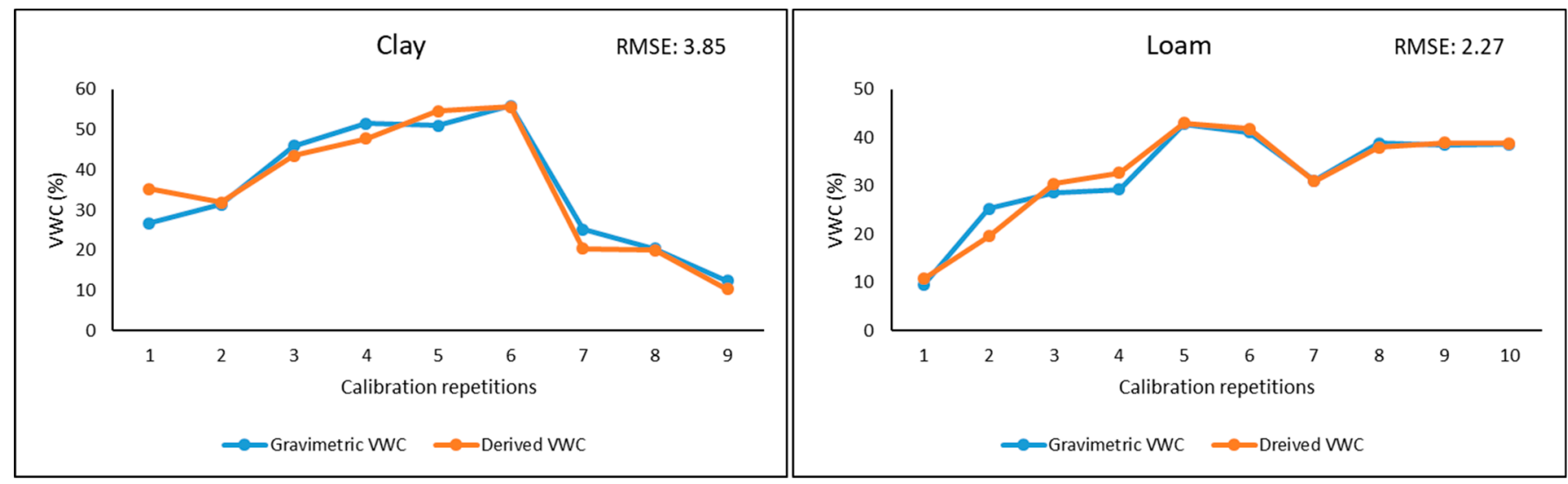

Figure 10. Clay and Loam Gravimetric VWC compared with derived VWC.

Table 9. Statistical metrics associated with coefficients of various calibration equations (Laboratory calibration-Phase 1).

\begin{tabular}{cccccccc}
\hline Soil Type & Calibration Name & Coefficient A & Coefficient B & Coefficient C & $\mathbf{R}^{\mathbf{2}}$ & $\boldsymbol{p}$-Value & RMSE (\%) \\
\hline Clay & Lab Calibration-Clay & 0.0093 & 1 & 0.4529 & 0.92 & $1.96 \times 10^{-5}$ & 3.85 \\
Loam & Lab Calibration-Loam & 0.0143 & 1 & 0.2818 & 0.83 & 0.01 & 2.27 \\
\hline
\end{tabular}
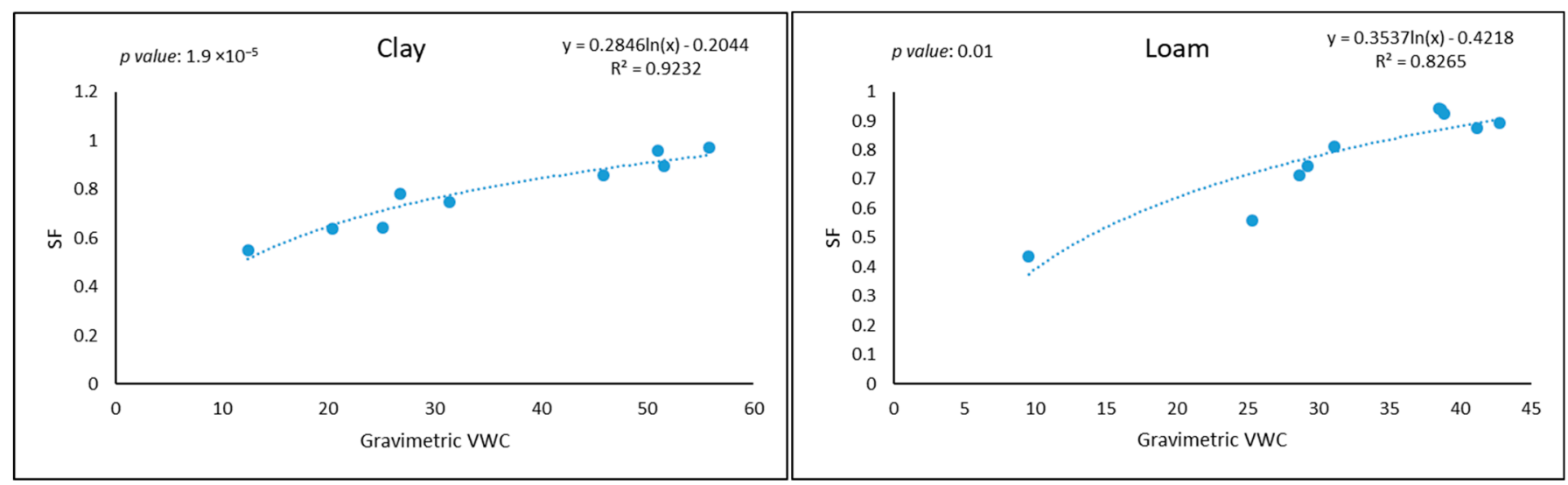

Figure 11. Fitting regression analysis of laboratory calibration.

\subsection{The Impact of Sample Disturbance-Compaction}

Sampling from disturbed soil may introduce additional errors due to the different levels of artificial compaction. This is noted in the low bulk densities of the loam samples given in Table 10. These values around $0.7 \mathrm{~g} / \mathrm{cm}^{3}$ are very low and probably due to the artificial loosening by the sampling and sample processing. The large, massive chunks were broken, and a relatively good, loose structure was created. Bulk density was calculated as an additional experimental factor to observe the impact of compression on the pore spaces volumetric water content in loam texture soil. Two conditions were chosen; dry and wet conditions to see the effect of compression on both extremes. Dry and wet soils were bulk sampled, compacted, and uncompacted to characterize the potential magnitude of the 
introduced error. In theory, bulk density increases as compaction are applied and decreases the total porosity, resulting in increased VWC for the lower water contents dominated by capillarity water and solid surface water absorption. The opposite is expected for the saturated soils, where compaction decreases the available pore space. The results showed what is expected in reality that for relatively dry soil conditions, the less the bulk density, the lower the water content, and the more the bulk density, the higher the water content for the same soil material.

Table 10. Bulk densities of Loam texture soil.

\begin{tabular}{|c|c|c|c|c|c|c|c|}
\hline \multicolumn{8}{|c|}{ December-20 } \\
\hline \multicolumn{2}{|c|}{ Dry Uncompressed } & \multicolumn{2}{|c|}{ Dry Compressed } & \multicolumn{2}{|c|}{ Wet Uncompressed } & \multicolumn{2}{|c|}{ Wet Compressed } \\
\hline $\begin{array}{c}\text { Moisture } \\
\text { Avg [v/v\%] }\end{array}$ & $\begin{array}{c}\text { Bulk } \\
\text { Density Avg } \\
{\left[\mathrm{g} / 100 \mathrm{~cm}^{3}\right]}\end{array}$ & $\begin{array}{c}\text { Moisture } \\
\text { Avg [v/v\%] }\end{array}$ & $\begin{array}{c}\text { Bulk } \\
\text { Density Avg } \\
{\left[\mathrm{g} / 100 \mathrm{~cm}^{3}\right]}\end{array}$ & $\begin{array}{c}\text { Moisture } \\
\text { Avg [v/v\%] }\end{array}$ & $\begin{array}{c}\text { Bulk } \\
\text { Density Avg } \\
{\left[\mathrm{g} / 100 \mathrm{~cm}^{3}\right]}\end{array}$ & $\begin{array}{c}\text { Moisture } \\
\text { Avg [v/v\%] }\end{array}$ & $\begin{array}{c}\text { Bulk } \\
\text { Density Avg } \\
{\left[\mathrm{g} / 100 \mathrm{~cm}^{3}\right]}\end{array}$ \\
\hline 29.41 & 65.55 & 32.82 & 73.61 & 30.60 & 67.01 & 45.71 & 89.01 \\
\hline
\end{tabular}

\subsection{Application of Derived Calibration Equation}

The last step of the study involved applying derived equations to a study area where the EnviroScan sensors are currently deployed to check the accuracy of the calibration equations. This reapplication exercise was performed on the same field where the loam sample was taken from two locations with similar soils were selected $50 \mathrm{~m}$ from each other. The plow layer was sampled in three depths, $0-10 \mathrm{~cm}, 10-20 \mathrm{~cm}$, and $20-30 \mathrm{~cm}$. The soil material for the three depths is expected to be the same due to tillage mixing. This way, the number of repetitions could be increased to six, using only two sites. The two locations in three depths were sampled, so six pairs of bulk samples were taken and compared with the estimated data derived using our laboratory calibrated estimation algorithm. The results showed that the calibration equation overestimated VWC by a $9 \%$ to $13 \%$ absolute difference in soil water content (Figure 12). This means there is still room for improvement as the recorded difference is still high; however, the regression results show a fair correlation $\left(R^{2}=0.65\right)$ between scaled frequency from the EnviroScan sensor and the gravimetric measurements (Figure 13). One potential source of the overestimation is the different compaction status of the homogenized soil material used in the laboratory than what the field soil material had.

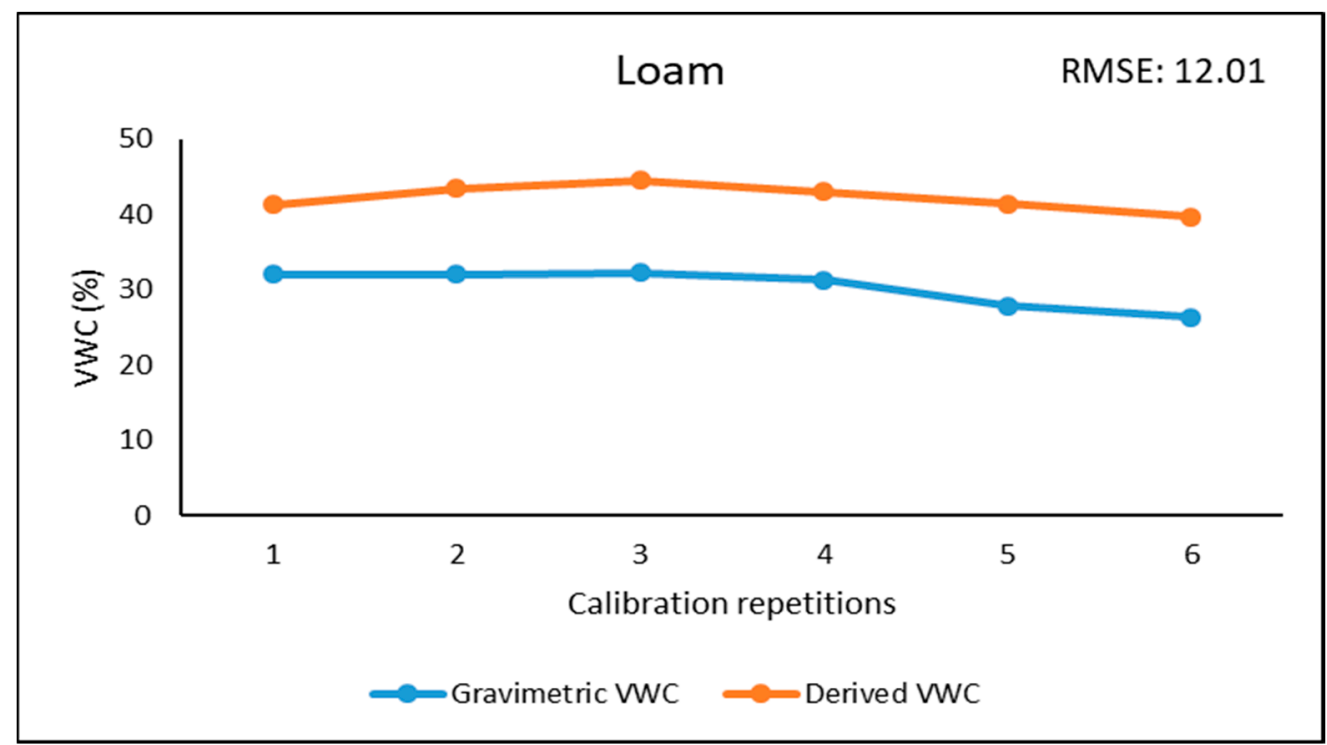

Figure 12. Loam Field VWC compared with derived VWC. 


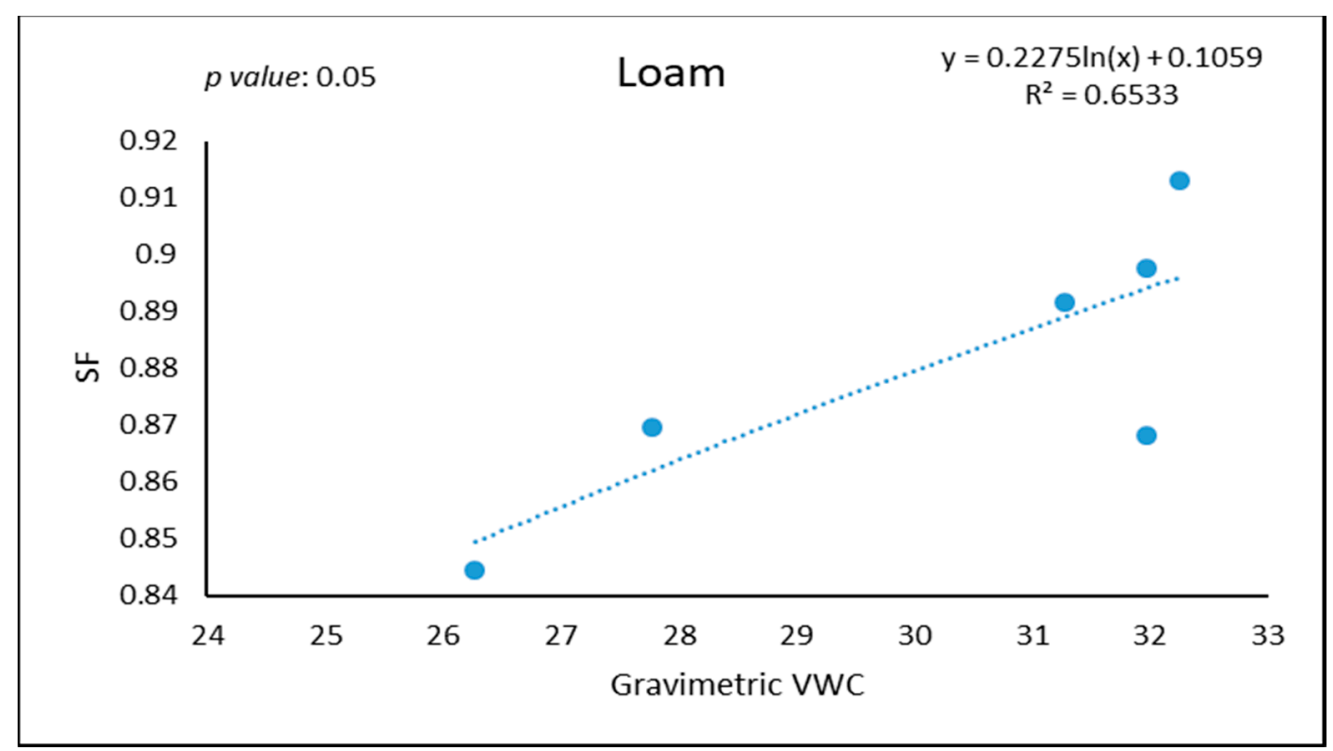

Figure 13. Fitting regression analysis of the derived calibration equation for Loam soils.

\section{Discussion}

Calibration is one of the greatest challenges for field soil moisture measurements. The installation is time-dependent. Any disturbance of the site will decrease the representativity of the measuring site. However, the variability of soil structural properties is very high and varies locally, of which this conflict is difficult to overcome. Calibration with high reliability can be achieved only with soil samples taken right next to the probe, but sampling in the sensed volume will change the soil properties and decrease the representativity.

The EnviroScan sensors were calibrated using field and laboratory measurements. The calibration Equations (7)-(9) were developed by comparing the sensors' measurements (Scaled Frequencies, SF) with the soil water contents obtained from the gravimetric method using logarithmic regression equations. The $p$-value of the regression results is significant. The derived equations that yielded the highest statistical correlation between volumetric water content from gravimetric and scaled frequencies were:

$$
\begin{aligned}
& \text { Clay: } \theta_{\mathrm{v}}=((\mathrm{SF}-0.4521) / 0.0092)^{\wedge} 1 / 1 \\
& \text { Loam: } \theta_{\mathrm{v}}=((\mathrm{SF}-0.3137) / 0.0161)^{\wedge} 1 / 1 \\
& \text { Sand: } \theta_{\mathrm{v}}=((\mathrm{SF}-0.4106) / 0.0082)^{\wedge} 1 / 1
\end{aligned}
$$

\subsection{Model Performance}

Statistical metrics associated with coefficients of various calibration equations are presented in the summary of results (Table 11). Our best model results for dominant clay soils $\left(R^{2}=0.92\right)$ were from laboratory calibration using equation 6 . This is an improvement from the results obtained by best fitting Sentek manufacturer equation, [23] $\left(R^{2}=0.58\right)$, Evett et al. [24] $\left(R^{2}=0.9\right)$, Burgess et al. [27] $\left(R^{2}=0.80\right)$, Paraskevas et al. [29] $\left(R^{2}=0.87\right)$, and Gao et al. [32] $\left(\mathrm{R}^{2}=0.86\right)$ for soils with high clay content. Groves and Rose, [26] $\left(R^{2}=0.93\right)$, Evett et al. [28] $\left(R^{2}=0.99\right)$ model results were better than the results obtained in this study due to larger data sets resulting in better data representation. The laboratory results obtained for Loam soils recorded an $R^{2}$ of 0.83 . This is a marginal improvement from the best fitting manufacturers algorithm, which had an $\mathrm{R}^{2}$ of 0.82 . Geesing et al. [22] recorded similar results to ours with an $\mathrm{R}^{2}$ of 0.88 , though they used an exponential regression model, which performed fractionally better than the logarithmic regression model we used. In addition, Paraskevas et al. [29] also recorded an $\mathrm{R}^{2}$ of 0.87 from equations exported from the local calibration that outweighed the manufacturer default equation. Then, Leib et al. [25] obtained better results, recording an average $R^{2}$ of 0.94 
though the loam sample contained higher content silt, and default equations tend to favor the soils with more homogeneous particle size, like silt loam. Finally, for sandy soils, our results showed an improvement during wetting of soils, i.e., field calibration-phase 2 , and the results were similar to Jia et al. [2], who recorded an $R^{2}$ of 0.92 and also concluded that accuracy of the model improved under laboratory conditions by applying a soil specific calibration method. Morgan et al. [17] performed linear and exponential models in fine sands $\left(R^{2}=0.83\right)$ and concluded that default calibration equations-yielded $22 \%$ lower estimates than data regression.

Table 11. Summary of statistical metrics associated with coefficients of both field and laboratory calibration equations.

\begin{tabular}{|c|c|c|c|c|}
\hline Soil Type & Calibration Name & $\mathbf{R}^{2}$ & $p$-Value & RMSE (\%) \\
\hline \multirow{4}{*}{ Clay } & Sentek default equation & - & - & 13.77 \\
\hline & Best fitting manufacturer's algorithm & $(0.58)$ & - & 3.56 \\
\hline & Regression results of field measurements & 0.79 & 0.001 & 13.74 \\
\hline & Lab calibration results & 0.92 & $1.96 \times 10^{-5}$ & 3.85 \\
\hline \multirow{4}{*}{ Loam } & Sentek default equation & - & - & 17.81 \\
\hline & Best fitting manufacturer's algorithm & $(0.82)$ & - & 1.89 \\
\hline & Regression results of field measurements & 0.4 & 0.07 & 14.01 \\
\hline & Lab calibration results & 0.83 & 0.01 & 2.27 \\
\hline \multirow{4}{*}{ Sand } & Sentek default equation & - & - & 5.77 \\
\hline & Best fitting manufacturer's algorithm & $(0.97)$ & - & 2.05 \\
\hline & Regression results of field measurements Phase 1 & 0.84 & 0.003 & 5.82 \\
\hline & Regression results of field measurements Phase 2 & 0.91 & $1.25 \times 10^{-8}$ & 1.86 \\
\hline
\end{tabular}

$\mathrm{R}^{2}$ values in brackets are taken from the manufacturer's records.

\subsection{Evaluation of the Manufacturer's Equations}

In terms of estimated VWC, comparing results in Table 11 to literature, the default calibration equations are considered valid as found by Provenzano et al. [31]. However, it is noted that further refinement of results is necessary to achieve the best possible estimated VWC. As much as the EnviroScan manufacturer equations are valid, the major critique observed is that they tend to underestimate VWC, which is in agreement with Paltineanu and Starr, [13], Burgess et al. [27], and Zettl et al. [30], but also overestimates VWC as reported in Gabriel et al. [20] and Paraskevas et al. [29]. We found that over and underestimation are related to the equation rather than SM condition related. The default Sentek equation tends to severely overestimate SM in the dry soils and underestimate it for the wet ones. It shrinks the natural variation into a smaller range.

Several papers suggest field calibration [20,22,27,30-32], but it is only feasible when data is used afterward because any bulk sampling for gravimetric SM measurements would disturb the soil around the sensor. An alternative approach tested here was to sample the sensor's larger neighborhood, at least $1 \mathrm{~m}$ apart from the sensor several times, expecting different SM conditions. The results have not shown much improvement over using the default Sentek manufacturers sensor equation, mainly due to limited SM changes observed within the period. The artificial extension of the SM conditions- like field wettingimproved the estimation a lot, and better performance was achieved compared to the best fitting manufacturer's algorithm. However, this approach was feasible only for the sand texture with a high infiltration rate.

Laboratory calibration was tested by collecting disturbed soil samples from the plow layers of clayey and loamy soils and applying different amounts of water for wetting the soil until saturation. Bulk sampling and sensor readings were done in several SM stages, and these data pairs were used to derive the calibration equation. This approach provided 
the best results but still could not outperform the best fitting equation results. Furthermore, when the equation was reapplied for another dataset from the same area with the same soils but in field conditions, the performance had dropped much below the regular best fitting equations. This can be explained by the soil samples' significant structural changes due to sampling and processing that change the major characteristics of the soils compared to field conditions.

The sphere of influence of the capacitance probe is small, with a main radial sensitivity range of $10 \mathrm{~cm}$ (Paltineanu and Starr 1997) from the access tubes. As such, the core samples for the laboratory analysis and the post-calibration for the loam reapplication in the present study were intentionally taken within this range. The small-range heterogeneity of soil texture and soil moisture can be a significant source of measurement variation, both in natural and agricultural field conditions. The relatively small volume of the sensed soil makes this problem of representativity even more serious. Therefore, the use of core sampling data collected beyond the main sensitivity sphere is a potential source of uncertainty, even if taken with the largest care. The success of off-site sampling from the vicinity of the access tube depends on two assumptions. The first is that the soil moisture content at a distance of $<100 \mathrm{~cm}$ is believed to be spatially dependent. The second assumption is that all spatial discontinuity caused by short-term fluctuations and sampling errors are random. In reality, neither of them are necessarily true in this small volume, where even one large root can make a difference. We found that this spatial heterogeneity is reflected in the bulk sampling results and highlighted by Geesing et al., 2004. This impact is even more expressed when disturbed soil samples are used to fill the ring, as it happened in the laboratory exercise.

Despite concerns about different zones of influence and the effect of small-range changes in soil water content, especially in heterogeneous soils, the findings show that the calibration approach proposed provides appropriate calibration equations for portable capacitance sensors in heterogeneous fields. Simple off-site field calibration provides an $R^{2}$ around $0.7-0.8$ for sand and clay, which is a fair performance for practical use, of which Geesing et al. (2004) reported similar values. However, for better refinement of results, laboratory measurements should cover a full range of SM values and achieve a better match. Geesing et al. (2004) used a similar off-site sampling approach to run the calibration with over 280 samples. In our study, similar performance was achieved using much less sample, averaging around 10 for a site, which means that fair performance can be achieved with fewer samples, but the covered range of SM values is rather crucial. Individual laboratory experiments should be performed with special care for field representativity - most importantly, the bulk density-because the reapplication of the precisely fitted laboratory curve in the field performs much less than the laboratory one.

\section{Conclusions}

Calibration and validation of the operational soil moisture sensors deployed to assist agricultural production and irrigation control are difficult. The field conditions are changing annually and defined by the applied tillage methods. Reliable measurements can be achieved only if the sensors are deployed into the same soil environment, condition as of the rest of the field, so they should be deployed after seedbed creation. The deployed sensors are expected to provide data from deployment time, so there is no long field calibration time. Disturbance of the sensor neighborhood should be avoided as well, which makes the traditional calibrations difficult.

This study aimed to compare several potential solutions for calibrating an EnviroScan sensor. The results show that the default calibration equations in all three classes have relatively low performances; however, significant refinement was achieved by selecting texture-specific equations from the manufacturer's libraries. The soil-specific equations of the EnviroScan often yielded quite satisfactory results with improvements in $R^{2}$ values and lowered RMSE's ranging between 2 and 4. 
Both field (phase 2) and laboratory calibration approaches can be used to calibrate EnviroScan sensors. Field calibration using bulk samples taken from the larger neighborhood to keep the measuring site undisturbed is a feasible approach. However, it may introduce significant uncertainty due to the large soil structural variability. It is also difficult to represent the full range of SM conditions, limiting the model development. Complementing the natural field samples/conditions with laboratory measurements of extreme dry and wet soil conditions significantly improved the field sampling. Laboratory measurements can only be done using disturbed samples. The results of the laboratory calibration are often very good, but the reapplication of these equations in the field do not perform as well, even if applied in the same area where the sample was taken. The disturbed samples have a different structure, bulk density, and porosity, making a difference compared to the actual field conditions. Despite the limitations, both approaches improved the model performance and reduced models' errors in all three soil textures. The sand and clay texture equations perform more consistently; any selection of texture-specific algorithms improve the estimation at a more or less equal level. They may not even need to be calibrated; the manufacturer's equation can be used for operational use. The loam texture-by definitionis not as homogeneous class as the other two. There is a significant variation among the loam equations' performances; therefore, the different kinds of loams may require a specific selection of the best fitting, most adequate algorithm.

Overall, the SM sensing technology is proved to work when site-specific calibration is applied. A very good fit of observed and estimated SM values can be achieved by a thorough calibration exercise, improving the estimation accuracy. Existing texturebased algorithms are always better than any default and suggested to be used. Sampling from a larger neighborhood for comparison and calibration can help select the best fitting algorithm, especially when laboratory measurements of extreme SM conditions can complement the field data.

Author Contributions: Conceptualization, D.K. and E.D.; methodology, D.K. and E.D.; software, D.K.; formal analysis, D.K. and E.D.; investigation, D.K.; writing-original draft preparation, D.K.; writing-review and editing, D.K. and E.D.; visualization, E.D.; supervision, E.D. Both authors have read and agreed to the published version of the manuscript.

Funding: The research was carried out within the GINOP-2.3.2-15-2016- 00031 "Innovative solutions for sustainable groundwater resource management" project of the Faculty of Earth Science and Engineering of the University of Miskolc in the framework of the Széchenyi 2020 Plan, funded by the European Union.

Institutional Review Board Statement: The study did not require ethical approval.

Informed Consent Statement: Not applicable.

Data Availability Statement: The data presented in this study are available on request from the corresponding author. The data are not publicly available because it was downloaded directly from the capacitance probe.

Conflicts of Interest: The authors declare no conflict of interest. The funders had no role in the design of the study, in the collection, analyses, or interpretation of data, in the writing of the manuscript, or in the decision to publish the results.

\section{References}

1. Roberti, J.A.; Ayres, E.; Loescher, H.W.; Tang, J.; Starr, G.; Durden, D.J.; Smith, D.E.; de la Reguera, E.; Morkeski, K.; McKlveen, M.; et al. A Robust Calibration Method for Continental-Scale Soil Water Content Measurements. Vadose Zone J. 2018, $17,170177$. [CrossRef]

2. Jia, J.; Zhang, P.; Yang, X.; Zhen, Q.; Zhang, X. Comparison of the accuracy of two soil moisture sensors and calibration models for different soil types on the loess plateau. Soil Use Manag. 2020, 1-11. [CrossRef]

3. Al-Ghobari, H.M.; Said, M.; El, A. Field evaluation of EnviroSCAN performance for monitoring soil water content compared with other soil moisture sensors under arid conditions. Wulfenia J. 2013, 20, 54-70.

4. Ling, P. Florinet Floriculture Newsletter-MOISTURE SENSORS A Review of Soil Moisture Sensors. Ohio, USA. 2005. Available online: https://hcs.osu.edu/sites/hcs/files/imce/files/soil-moisture-sensors.pdf (accessed on 12 November 2020). 
5. Morgenschweis, G. Soil-water movement and balance in thick loess soils and its model simulation. J. Hydrol. 1984, 67, 339-360. [CrossRef]

6. Robinson, D.A.; Jones, S.B.; Wraith, J.M.; Or, D.; Friedman, S.P. A Review of Advances in Dielectric and Electrical Conductivity Measurement in Soils Using Time Domain Reflectometry. Vadose Zone J. 2003, 2, 444-475. [CrossRef]

7. Bello, Z.A.; Tfwala, C.M.; van Rensburg, L.D. Evaluation of newly developed capacitance probes for continuous soil water measurement. Geoderma 2019, 345, 104-113. [CrossRef]

8. Fares, A.; Alva, A.K. Evaluation of capacitance probes for optimal irrigation of citrus through soil moisture monitoring in an entisol profile. Irrig. Sci. 2000, 19, 57-64. [CrossRef]

9. Mazahrih, N.T.; Katbeh-Bader, N.; Evett, S.R.; Ayars, J.E.; Trout, T.J. Field Calibration Accuracy and Utility of Four Down-Hole Water Content Sensors. Vadose Zone J. 2008, 7, 992-1000. [CrossRef]

10. Sentek Technologies Inc. Soil Moisture and Data Probes | Sentek Sensor Technologies. 2011. Available online: https:// sentektechnologies.com/product-range/soil-data-probes / (accessed on 12 November 2020).

11. Al-Ghobari, H.; Marazky, M.; Aboukarima, A.; Minyawi, M. Calibration of Soil Water Content Data from EnviroSCAN System Using Artificial Neural Network. Am. J. Exp. Agric. 2016, 12, 1-11. [CrossRef]

12. Mead, R.; Ayars, J.; Lui, J. Evaluating the influence of soil texture, bulk density and soil water salinity on a capacitance probe calibration. In American Society of Agricultural Engineers Paper 95-3264; American Society of Agricultural Engineers: Michagan, MI, USA, 1995.

13. Paltineanu, I.C.; Starr, J.L. Real-time Soil Water Dynamics Using Multisensor Capacitance Probes: Laboratory Calibration. Soil Sci. Soc. Am. J. 1997, 61, 1576-1585. [CrossRef]

14. Campora, M.; Palla, A.; Gnecco, I.; Bovolenta, R.; Passalacqua, R. The laboratory calibration of a soil moisture capacitance probe in sandy soils. Soil Water Res. 2019, 15, 75-84. [CrossRef]

15. Kassaye, K.T.; Boulange, J.; Saito, H.; Watanabe, H. Calibration of capacitance sensor for Andosol under field and laboratory conditions in the temperate monsoon climate. Soil Tillage Res. 2019, 189, 52-63. [CrossRef]

16. Provenzano, G.; Rallo, G.; Duarte Guedes Cabral de Almeida, C.; Gomes de Almeida, B. Development and validation of a New Calibration Model for Diviner $2000{ }^{\circledR}$ probe Based on Soil Physical Attributes. Water 2020, 12, 3414. [CrossRef]

17. Morgan, K.T.; Parsons, L.R.; Wheaton, T.A.; Pitts, D.J.; Obreza, T.A. Field Calibration of a Capacitance Water Content Probe in Fine Sand Soils. Soil Sci. Soc. Am. J. 2009, 63, 987-989. [CrossRef]

18. Busscher, W.J. Field Estimation of Soil Water Content: A review. J. Soil Water Conserv. 2009, 64, 116A. [CrossRef]

19. Hajdu, I.; Yule, I.; Bretherton, M.; Singh, R.; Hedley, C. Field performance assessment and calibration of multi-depth AquaCheck capacitance-based soil moisture probes under permanent pasture for hill country soils. Agric. Water Manag. 2019, 332-345. [CrossRef]

20. Gabriel, J.L.; Lizaso, J.I.; Quemada, M. Laboratory versus Field Calibration of Capacitance Probes. Soil Sci. Soc. Am. J. 2010, 74, 593-601. [CrossRef]

21. Jabro, J.D.; Leib, B.G.; Jabro, A.D. Estimating soil water content using site-specific calibration of capacitance measurements from Sentek EnviroSCAN systems. Appl. Eng. Agric. 2005, 21, 393-399. [CrossRef]

22. Geesing, D.; Bachmaier, M.; Schmidhalter, U. Field calibration of a capacitance soil water probe in heterogeneous fields. Aust. J. Soil Res. 2004, 42, 289-299. [CrossRef]

23. Sentek Technologies Inc. Calibration Manual for Sentek Soil Moisture Sensors. 2001. Available online: https://sentektechnologies. $\mathrm{com} /$ download/moisture-calibration-manual/ (accessed on 12 January 2021).

24. Evett, S.; Laurent, J.P.; Cepuder, P.; Hignett, C. Neutron scattering, capacitance, and TDR soil water content measurements compared on four continents. In Proceedings of the 17th WCSS, Bangkok, Thailand, 14-21 August 2002; Volume 59, p. 1021-1.

25. Leib, B.G.; Jabro, J.D.; Matthews, G.R. Field evaluation and performance comparison of soil moisture sensors. Soil Sci. 2003, 168, 396-408. [CrossRef]

26. Groves, S.J.; Rose, S.C. Calibration equations for Diviner 2000 capacitance measurements of volumetric soil water content of six soils. Soil Use Manag. 2004, 20, 96-97. [CrossRef]

27. Burgess, P.J.; Reinhard, B.R.; Pasturel, P. Compatible measurements of volumetric soil water content using a neutron probe and Diviner 2000 after field calibration. Soil Use Manag. 2006, 22, 401-404. [CrossRef]

28. Evett, S.R.; Tolk, J.A.; Howell, T.A. Soil Profile Water Content Determination: Sensor Accuracy, Axial Response, Calibration, Temperature Dependence, and Precision. Vadose Zone J. 2006, 5, 894-907. [CrossRef]

29. Paraskevas, C.; Georgiou, P.; Ilias, A.; Panoras, A.; Babajimopoulos, C. Calibration equations for two capacitance water content probes. Int. Agrophysics 2012, 26, 285-293. [CrossRef]

30. Zettl, J.D.; Huang, M.; Lee, B.S.; Si, B.C. Étalonnage Des Sondes Á Capteurs Capacitifs Multiples D’Aprés La Densité Dans Les Sols Á Texture Grossiére. Can. J. Soil Sci. 2015, 95, 331-336. [CrossRef]

31. Provenzano, G.; Rallo, G.; Ghazouani, H. Assessing Field and Laboratory Calibration Protocols for the Diviner 2000 Probe in a Range of Soils with Different Textures. J. Irrig. Drain. Eng. 2016, 142, 04015040. [CrossRef]

32. Gao, Z.; Zhu, Y.; Liu, C.; Qian, H.; Cao, W.; Ni, J. Design and test of a soil profile moisture sensor based on sensitive soil layers. Sensors 2018, 18, 1648. [CrossRef] [PubMed]

33. Soil Survey Division Staff. Soil Survey Manual, Handbook No. 18; United States Department of Agriculture: Washington, DC, USA, 2017. 
34. Buss, P. The use of capacitance based measurements of realtime soil water profile dynamics for irrigation scheduling. In National Conference Irrigation Association; Australia and National Committee Irrigation Drainage: Lauceston, Tasmania, 1993; pp. 17-19.

35. Dane, J.; Topp, G. (Eds.) Methods of Soil Analysis, Part 4-Physical Methods; Soil Science Society of America Inc.: Madison, WI, USA, 2002.

36. Kelleners, T.; Soppe, R.; Ayars, J.; Skaggs, T. Calibration of Capacitance Probe Sensors in a Saline Silty Clay Soil. Soil Sci. Soc. Am. J. 2004, 68, 770-778. [CrossRef]

37. De Rosny, G.; Chanzy, A.; Parde, M.; Gaudu, J.; Frangi, J.; Laurent, J. Numerical Modelling of a Capacitance Probe Response. Soil Sci. Soc. Am. J. 2001, 65, 13-18. [CrossRef]

38. Scobie, M. Sensitivity of Capacitance Probes to Soil Cracks. Bachelor's Thesis, University of Southern Queensland, Toowomba, Australia, 2006. Available online: https:/ / eprints.usq.edu.au/2227/ (accessed on 8 February 2021).

39. Kutilek, M.; Nielsen, D.R. Soil Hydrology: Textbook for Students of Soil Science, Agriculture, Forestry, Geoecology, Hydrology, Geomorphology and Other Related Disciplines; Catena Verlag: Cremlingen-Destedt, Germany, 1994.

40. Starr, J.L.; Paltineanu, I.C. Soil Water Dynamics Using Multisensor Capacitance Probes in Nontraffic Interrows of Corn. Soil Sci. Soc. Am. J. 1998, 62, 114-122. [CrossRef] 